ARTICLE

\title{
Victoria continental microplate dynamics controlled by the lithospheric strength distribution of the East African Rift
}

\author{
Anne Glerum (iD ${ }^{1 凶}$, Sascha Brune (iD ${ }^{1,2}$, D. Sarah Stamps $\mathbb{B}^{3}$ \& Manfred R. Strecker ${ }^{2}$
}

The Victoria microplate between the Eastern and Western Branches of the East African Rift System is one of the largest continental microplates on Earth. In striking contrast to its neighboring plates, Victoria rotates counterclockwise with respect to Nubia. The underlying cause of this distinctive rotation has remained elusive so far. Using 3D numerical models, we investigate the role of pre-existing lithospheric heterogeneities in continental microplate rotation. We find that Victoria's rotation is primarily controlled by the distribution of rheologically stronger zones that transmit the drag of the major plates to the microplate and of the mechanically weaker mobile belts surrounding Victoria that facilitate rotation. Our models reproduce Victoria's GPS-derived counterclockwise rotation as well as key complexities of the regional tectonic stress field. These results reconcile competing ideas on the opening of the rift system by highlighting differences in orientation of the far-field divergence, local extension, and the minimum horizontal stress.

\footnotetext{
${ }^{1}$ Helmholtz Centre Potsdam - GFZ German Research Centre for Geosciences, Potsdam, Germany. ${ }^{2}$ University of Potsdam, Potsdam-Golm, Germany.

${ }^{3}$ Virginia Tech, Blacksburg, VA, USA. ${ }^{凶}$ email: acglerum@gfz-potsdam.de
} 
T he East African Rift System (EARS) is the largest Cenozoic continental rift system. Its Eastern Branch stretches from Afar to the Tanzania divergence, while its western branch stretches from northern Uganda to Mozambique. These two rift branches accommodate divergence between the major Nubian and Somalian plates, and together with diffuse zones of deformation in the southwest Indian Ocean, they delineate the Victoria (hereafter referred to as Victoria), Rovuma, and Lwandle microplates $^{1,2}$ (Fig. 1a). Global positioning system (GPS) and earthquake slip data allowed for quantifying the current motion of all involved plates ${ }^{1-3}$, demonstrating that Somalia, Rovuma, and Lwandle rotate clockwise with respect to Nubia. It, however, also became clear that Victoria's rotation constitutes a remarkable exception ${ }^{1,3-6}$. The Victoria microplate was found to rotate counterclockwise with respect to the Nubian plate around an Euler pole several hundred kilometers north of the plate (see black arrows and purple stars in Fig. 1a).

The driving mechanism behind the rotation of the Victoria microplate, outlined by faulting, seismicity, and volcanism, has remained enigmatic ${ }^{3}$. It has been suggested that northeastward asthenospheric flow could exert basal drag on the keel of the Tanzania craton $^{1}$, which underlies large parts of the Victoria microplate (Fig. 1b). Interpreting numerical models of the EARS, other studies inferred that asymmetrical plume or double-plume impingement on the keel of the Tanzania craton might generate sufficient torque to drive Victoria rotation ${ }^{12,13}$. None of these studies quantified the required plume forcing and microplate rotation in detail. Large-scale numerical mantle flow simulations, however, suggest only a limited impact of basal shear tractions on East African plate kinematics ${ }^{14,15}$.

Here, we propose the hypothesis that Victoria rotation is controlled by the first-order geometry of adjacent rift arms, whose orientation is guided by the inherited distribution of mechanically stronger and weaker lithospheric domains. This hypothesis is inspired by previous observations of rotating oceanic microplates between two spreading centers, for which edge-driven microplate kinematics were proposed ${ }^{16}$, during which drag of the surrounding plates on the microplate's edges drives rotation around a vertical axis. These fast-rotating ${ }^{16,17}$, short-lived $\left(\sim 5-10 \mathrm{My}^{18}\right)$ accreting oceanic microplates are bounded by weak overlapping ridge segments and by stronger coherent young oceanic lithosphere in the overall plate-boundary direction ${ }^{19,20}$. In East Africa, the plate-boundary configuration is similar, albeit at a much larger scale (Fig. 1b): the curved Eastern and Western Branches of the EARS delimiting Victoria run orthogonal to the regional relative extension direction and follow lithospheric suture zones formed during several Proterozoic orogenies ${ }^{21-24}$ (dashed areas in Fig. 1b). At the Tanzania divergence, the Eastern Branch separates into three strands that, in part, die out against the strong lithosphere of the Archean Tanzania craton ${ }^{25,26}$. Similarly, in northern Uganda, the Western Branch terminates at Precambrian fabric, the NW-trending Aswa Shear Zone ${ }^{27}$. The Aswa Shear Zone is in proximity to the location of a WNW-ESE trending, failed, early Cretaceous rift basin that is also traversed by the Eastern $\mathrm{Branch}^{28}$. This possibly polyphase rift $^{29}$, which initiated the Turkana depression and the Anza graben ${ }^{30}$, significantly thinned the continental crust ${ }^{31}$. After thermal equilibration of the thinned radiogenic crust and the lithosphere, this failed rift now constitutes a mechanically strong region that is thought to affect the progression of the Main Ethiopian Rift and the Kenya rift approaching from the north and south, respectively 32,33

Although rotating microplates have been observed as specific modes of rift or ridge segment interaction in analog and numerical models $s^{17,20,32,34-36}$, it is unknown thus far whether the edge-driven mechanism ${ }^{16}$ applies to the rotation of large continental blocks like Victoria. In nature, in contrast to oceanic microplates, their continental counterparts generally evolve within complex inherited structures associated with previous episodes of mountain building or rifting ${ }^{22,37-40}$, and it is unclear how these anisotropies affect microplate rotation. In this study, we first use generic 3D numerical models to confirm edge-driven rotation of a Victoria-scale continental microplate, and to determine first- and second-order controls on such microplate rotation. Second, we demonstrate the applicability of the edgedriven mechanism to Victoria, in particular, by comparing the results of an EARS-specific numerical model to regional surface motions predicted from GNSS observations ${ }^{3}$. Finally, we compare the model-derived tectonic regime and stress field orientations with the respective EARS observations, providing a unifying perspective on plate kinematics and proposed stress sources of the EARS.

\section{Results}

Numerical model setup. We investigate the factors controlling generic and Victoria continental microplate rotation with the finite-element software ASPECT ${ }^{41-44}$. Our increasingly complex 3D model setups range from a generic, abstracted geometry of two arcuate rift branches within an otherwise homogeneous lithosphere to models specifically tailored to the EARS. The cuboid model domain of $2100 \times 2700 \times 300 \mathrm{~km}$ is initially filled with viscoplastic layers of the upper crust, lower crust, lithospheric mantle, and asthenosphere (Fig. 2; Supplementary Table 1), and a steady-state continental geotherm combined with an adiabatic mantle temperature profile. Mobile belts are represented by a raised Lithosphere-Asthenosphere Boundary (LAB); here deformation begins to localize under the outward velocity prescribed on the east and west boundaries. The configuration of the belts is characterized by the parameters defined in Fig. 2a.

Generic mobile belt configuration models. The generic reference model (Fig. 2a) that forms the basis of our exploration of controls on microplate rotation includes an initial thinning of the lithosphere of $17 \mathrm{~km}$ along the outline of an ellipse with a minor axis $a=375 \mathrm{~km}$ and a major axis $b=750 \mathrm{~km}$, comparable with the scale and geometry of the EARS as evident from the ellipse axes in Fig. 1b. The extent of the rift arm seed $\alpha$ is $90^{\circ}$. Due to initial thermal equilibration, the raised LAB reduces the strength of the lithosphere, which is a simplified approach to mimic the inherited weakness of mobile belts. We run the model for $10 \mathrm{My}$ of model time while applying an extension velocity $v_{x}$ of $2.5 \mathrm{~mm}$ $\mathrm{yr}^{-1}$ on both the left and right boundary, similar to what has been suggested for the EARS (see "Methods").

Figure 3 presents several snapshots of the reference model evolution. Deformation localizes along mobile belts, and as a consequence, the area inside the rift branches behaves progressively more rigidly. The velocity field shows $\mathrm{E}-\mathrm{W}$ motion of the major plates (as dictated by the boundary conditions), with some loss of speed toward the rift due to internal deformation of the plates. Within the area spanned by the rift arms, the velocity field shows a rotational pattern around the center of the microplate. This motion is described by an angular velocity of $0.1021^{\circ} \mathrm{My}^{-1}$ around the vertical rotation axis passing through the point $(x, y)=$ $(1053,2758) \mathrm{km}$ (in a western-plate fixed frame, Fig. 4). As expected for this symmetric setup, the pole is very close to the central $x$ coordinate $(x=1050 \mathrm{~km})$. It is worth noting that a mirrored mobile belt geometry (such that the rift branch coming from the north is deflected west and the southern branch east) produces the same, but clockwise, rotation of the microplate.

Within the two major plates, the maximum horizontal compressive stress is predominantly $\mathrm{N}-\mathrm{S}$ oriented. Inside the 
a

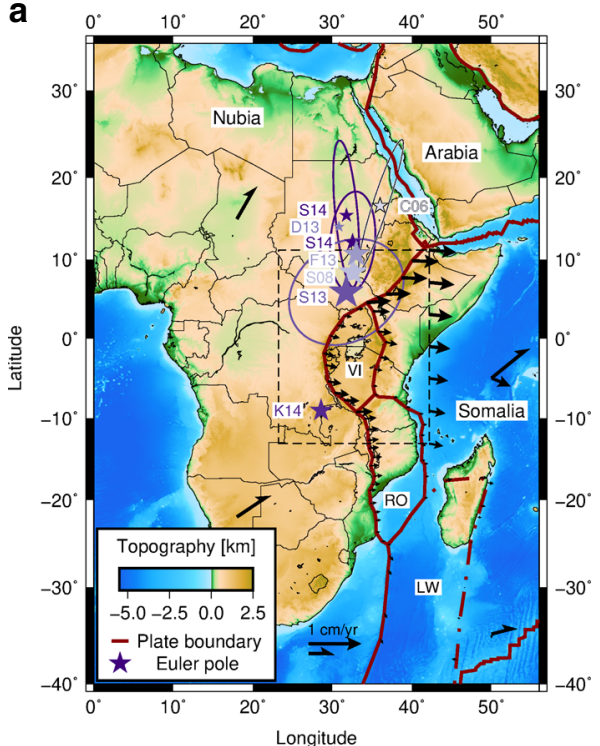

b

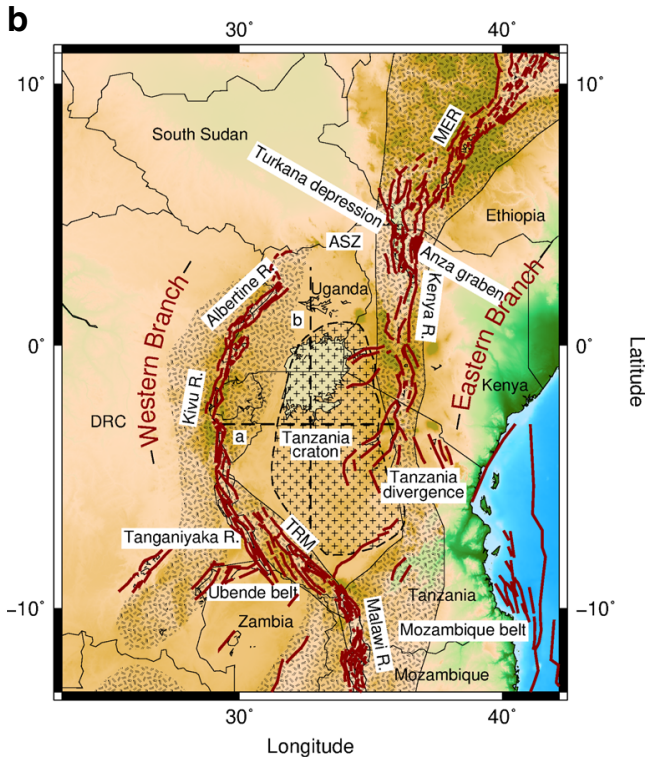

Fig. 1 Tectonic setting of the East African Rift System. a Plate kinematic configuration of the East African Rift System. Thick red lines represent block model plate boundaries ${ }^{2}$, including the Victoria (VI), Rovuma (RO), and Lwandle (LW) microplates. Black arrows indicate the absolute ${ }^{7}$ (halved vector heads) and relative ${ }^{3}$ (full vector heads) plate motions, albeit depicted in a different scale. Relative velocity vectors along the plate boundaries represent motion with respect to the plate to the west of the boundary; other relative motions are with respect to Nubia. The dashed black box indicates this study's model domain as well as the area shown in panel b. Purple stars indicate Euler poles describing the rotation of VI with respect to Nubia: $\mathrm{C06}^{1}$, S082 ${ }^{2}$, S135, $\mathrm{D} 13^{4}, \mathrm{~F} 13^{6}, \mathrm{~S} 14^{3}$, and $\mathrm{K} 14^{7}$. b Zoom-in showing individual rift faults from the GEM fault database ${ }^{8}$, forming the Western and the Eastern Branch. The Tanzania craton (crosses) is outlined in black dashes ${ }^{9}$; other dashed areas indicate the Proterozoic mobile belts ${ }^{10}$. The background in both panels shows the bedrock topography ${ }^{11}$. ASZ Aswa Shear Zone, TRM Tanganyika-Rukwa-Malawi rift segment, MER Main Ethiopian Rift.

rifts, however, the local extension direction and $\sigma_{\operatorname{Hmax}}$ deviate from the far-field extension and corresponding stress direction. In the curved rift segments, the stress orients itself at an angle to both the extension direction and the rift axis (Fig. 3e), a process that has been described in previous analog and numerical studies $^{45-47}$ of less complex setups. In front of the rift tips, $\sigma_{\mathrm{Hmax}}$ rotates such that it aligns with the outline of the ellipsoidal microplate.

We find that rift-parallel motion is the largest along the most oblique segments of the rift, up to $30 \mathrm{~km}$ over the full $10 \mathrm{My}$. The rotation of Victoria also results in block-parallel motion along the more diffuse microplate boundaries, but only up to $22 \mathrm{~km}$. The curved rift segments each accommodate between $\sim 19$ and $32 \mathrm{~km}$ of $\mathrm{E}-\mathrm{W}$ extension in $10 \mathrm{My}$ (the total applied extension is $50 \mathrm{~km}$ ). Figure 3 also shows that Nubia and Somalia plate motions outside the rift sections are E-W, while in the more coupled areas, the velocity field is deflected in the direction of rotation. Note that the entire motion field is point-symmetric around the center of the block (gray arrows in Fig. 3c).

In the following, we assess the impact of possible controls on the microplate rotation by varying, with respect to the above reference model, first the lateral distribution of weaknesses in terms of their extent (opening angle $\alpha$ ), their offset (ellipse minor axis $a$ ), and their symmetry (opening angles $\alpha_{\mathrm{W}}$ and $\alpha_{\mathrm{E}}$ ), then the lithospheric strength in terms of initial LAB-thinning amplitude (thinning factor $f$ ) and width (standard deviation $\sigma$ ), and finally the thickness of the microplate.

Varying the initial extent of the mobile belts between $30^{\circ}$ and $150^{\circ}$ in steps of $30^{\circ}$ predicts the derived rotation poles in Table 1 and Fig. 4q, while velocity, stress, and strain rate fields after 10 My are shown in Fig. 4a-e. The predicted angular velocity is the highest for an opening angle of $90^{\circ}$, and decreases with deviation from this optimum angle, accompanied by a northward shift of the rotation pole. These changes are not symmetric around $90^{\circ}$, however. For an extent of $30^{\circ}$, the strain rate field shows an ellipsoidal pattern of deformation, as well as two additional highstrain rate branches directly crossing the potential microplate area. From $90^{\circ}$ onward, the ellipsoidal area between the branches is seen to behave as a coherent block, which is also reflected in the low root-mean-square residual distance (RMSD) of the pole location (Table 1). For an extent of $150^{\circ}$, the rift arms connect to the straight rift segments to form a full ellipse, in effect prohibiting motion of the microplate. In all actively deforming areas, the tectonic stress regime is extensional, while in low strain rate areas, some strike-slip regimes result.

As shown in Table 1 and Fig. $4 \mathrm{c}$ and h, extending the width between the arms (increasing minor axis $a$, circle models) reduces the rotation velocity and increases the distance of the pole to the center of the domain. Decreasing the major axis $b$ to $375 \mathrm{~km}$ to obtain a smaller circular configuration leads to a smaller reduction of microplate rotation (Fig. 4f).

As for $a=375 \mathrm{~km}$, for circular mobile belt configurations ( $a=$ $750 \mathrm{~km}$ ), rotation velocity drops when the opening angle $\alpha$ is smaller than $90^{\circ}$ (Table 1 and Fig. 4g-i). However, changes in angular velocity and pole location are less evident for opening angles $>90^{\circ}$. Strike-slip regimes develop in the most oblique segments of the circular rifts with $\alpha \geq 90^{\circ}$.

EARS-like asymmetric opening angles of $\alpha_{\mathrm{W}}=160^{\circ}$ and $\alpha_{\mathrm{E}}=$ $120^{\circ}$ reduce the angular velocity of the microplate by a factor $\sim 2$ (Table 1 and Fig. 4q). The rotation pole is displaced northward and, moreover, to the east. This shift is due to the higher coupling along the eastern side of the microplate compared with the completely decoupled western side.

Varying the thinning factor $f$ and the rift axis normal extent of the seed $\sigma$ as detailed in Table 1 and Fig. $4 \mathrm{j}-\mathrm{m}$ shows that a thinning factor that is too small (model thick LAB seed) does not localize deformation in the rift arms. A thinner LAB, however, enhances localization, leading to an almost doubled angular 
a

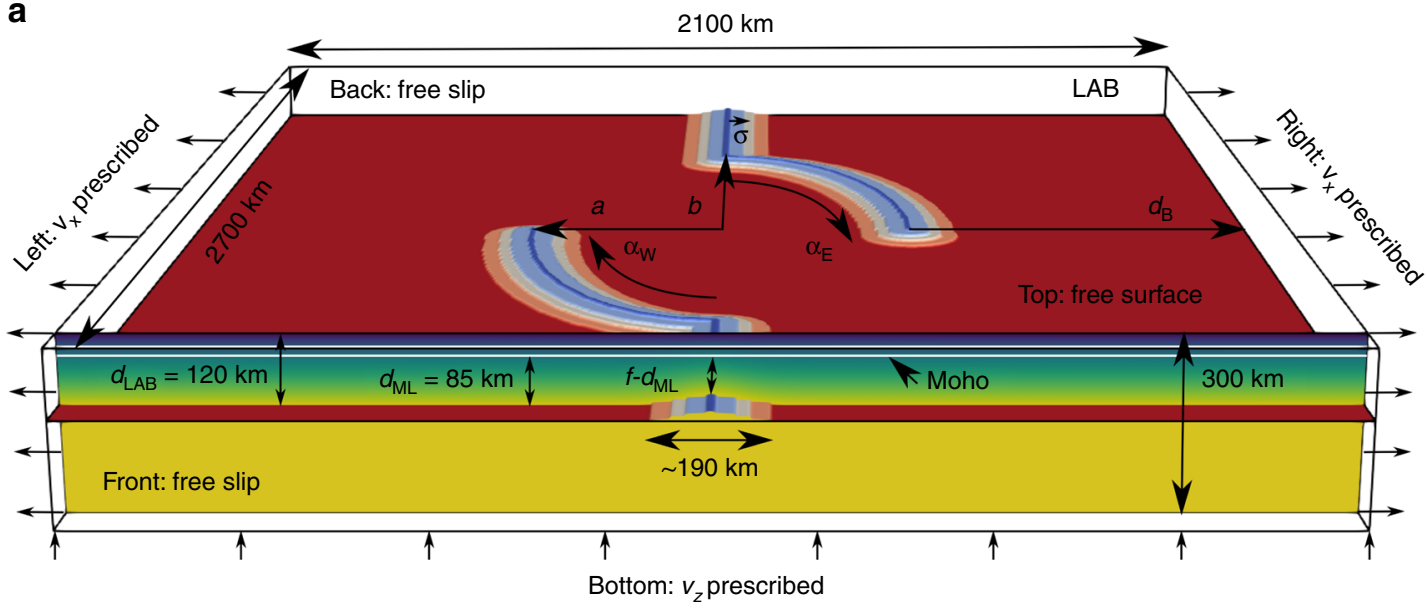

Bottom: $v_{z}$ prescribed

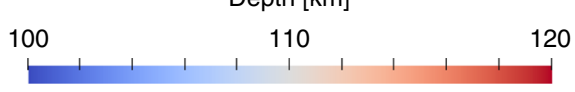

$0 \quad 127$

Temperature $\left[{ }^{\circ} \mathrm{C}\right]$

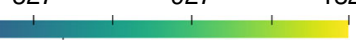

389558

b

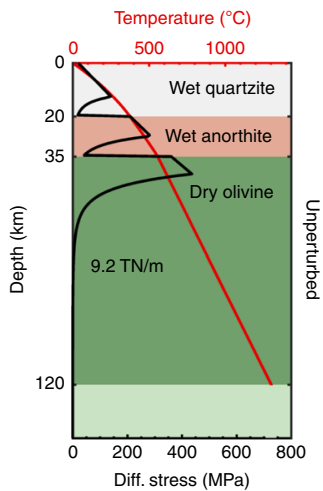

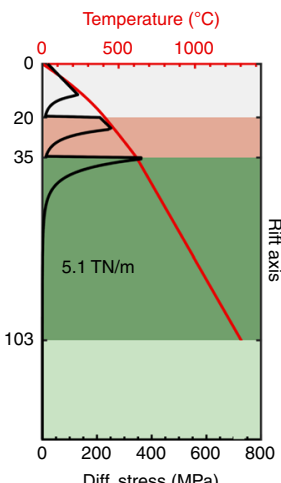

Diff. stress (MPa)
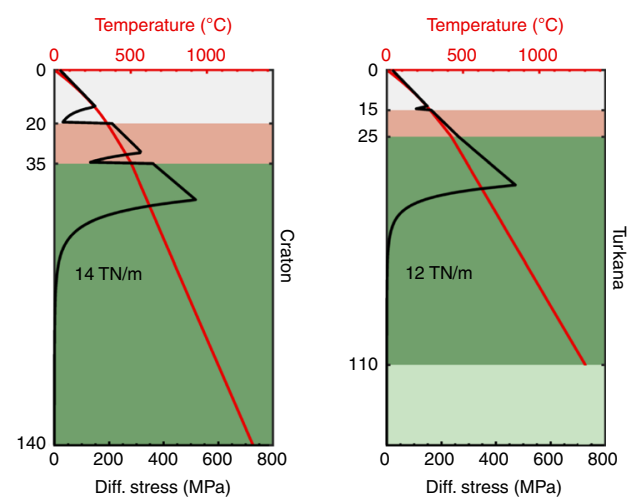

Fig. 2 Generic mobile belt configuration model setup and lithospheric strength profiles. a A raised Lithosphere-Asthenosphere Boundary (LAB, depth shown in blue-to-red colors) is used to mimic the mobile belts. The perturbed depth of the LAB is constructed using a Gaussian distribution with standard deviation $\sigma=50 \mathrm{~km}$ and amplitude (thinning factor) $f=0.8$. The lateral distribution of the perturbation can be divided into straight segments extending from the front and back domain boundaries and the curved segments that follow the outline of an ellipse centered at the midpoint of the domain, and can thus be characterized by the minor and major axes of the ellipse $a=375 \mathrm{~km}$ and $b=750 \mathrm{~km}$, and their opening angles $\alpha_{\mathrm{W}}=90^{\circ}$ and $\alpha_{\mathrm{E}}=90^{\circ}$. The minimum distance of the curved segments to the east and west boundaries is $d_{B}=675 \mathrm{~km}$. Prescribed velocities are $v_{x}=\frac{1}{2} \cdot 5 \mathrm{~mm} \mathrm{yr}^{-1}$ in the reference case. The vertical slice shows the initial temperature field (which includes the same perturbation) together with the laterally homogeneous crustal layers outlined in white. Temperatures at the upper/lower crust and Moho interfaces are indicated below the temperature scale bar. Top and bottom temperatures are fixed at 273 and 1594 K, respectively. b Lithospheric strength and temperature profiles at representative locations for a lithostatic pressure and background strain rate determined by the velocity boundary conditions of $\sim 8 \times 10^{-17} \mathrm{~s}^{-1}$.

velocity and rigid plates. A doubled mobile belt width has an insignificant effect on the model results, while a smaller $\sigma$ reduces the rotation of the microplate by up to $\sim 25 \%$.

Increased strength of the microplate due to a thicker lithosphere $(140,160$, or $180 \mathrm{~km})$ for a fixed crustal thickness induces more plate-like behavior of the microplate (i.e., lower internal strain rates in Fig. 4n-p and small RMSD in Table 1). However, rotation velocity decreases with increased thickness. Perhaps, the velocity decrease is caused by the interaction of the increasingly thick cratonic root with the mobile belts, reducing the initial LAB perturbation. The regions undergoing strike-slip faulting in the most oblique rift sections grow with craton thickness. Within the interior of the craton, the tectonic regime transitions from strike-slip to thrust faulting.

East African Rift System-specific mobile belt configuration models. In this second set of models, we account for first-order rift geometry of the EARS, including the asymmetry of the Western and Eastern Branches and the obliquity of the straight rift segments. As Fig. 5 shows, the realistic EARS geometry does not change the validity of the edge-driven microplate mechanism, but does affect the tectonic regime of specific areas. For example, within the Tanganyika-Rukwa-Malawi (TRM) segment, the tectonic regime transitions from normal faulting at $1 \mathrm{My}$, to strike-slip at $5 \mathrm{My}$, and oblique normal slip at $10 \mathrm{My}$. The other rift segments exhibit normal faulting only. Consistent with the generic model, the normal faults in the rift form at half the angle between the mobile belt trend and the local extension direction (which deviates from E-W). Over time, both the plate-like area and the rotation velocity increase (summarized in Table 2).

Predicted motion of the Nubian plate is E-W, except for some southward component near the northern rift tip; some northward movement is predicted for Somalia. Areas located within the microplate and to the east of the TRM segment have a significant 


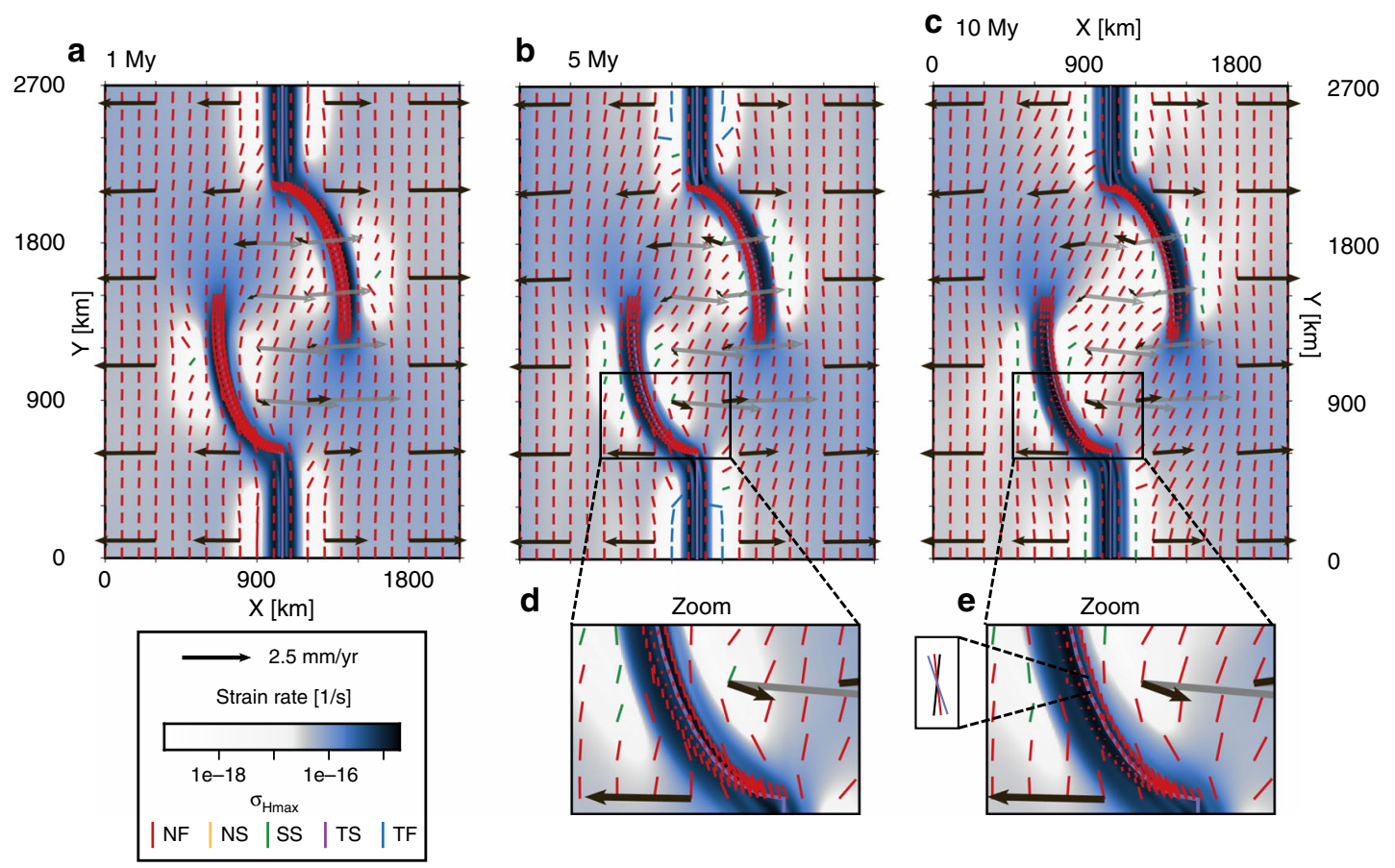

Fig. 3 Generic mobile belt configuration reference model Ellipse $\mathbf{9 0 ^ { \circ }}$ results. a-e Depicted are the strain rate field, maximum horizontal compressive stress $\sigma_{\mathrm{Hmax}}$ colored according to the tectonic regime, and the velocity vectors at 3-km depth at 1, 5, and $10 \mathrm{My}$. High-resolution $\sigma_{\mathrm{Hmax}}$ directions are plotted in an area of $100 \mathrm{~km}$ around the mobile belt axes if the strain rate exceeds $1 \times 10^{-16} \mathrm{~s}^{-1}$. Black vectors are plotted in the model frame of motion, while the dark-gray vectors represent the microplate motion in a Nubia-fixed frame. Black and gray vectors are scaled equally. Panels $\mathbf{d}$ and $\mathbf{e}$ show a zoomin of the oblique rift section in the boxed area indicated in $\mathbf{b}$ and $\mathbf{c}$, respectively. The inset in $\mathbf{e}$ illustrates characteristic local deviations from far-field kinematics by comparing $\sigma_{\mathrm{Hmax}}$ (red), rift trend (purple), and the orthogonal of the local extension direction (black). NF normal faulting, NS normal and strike-slip faulting, SS strike-slip faulting, TS thrust and strike-slip faulting, TF thrust faulting.

$\mathrm{N}-\mathrm{S}$ component of motion, in accordance with the counterclockwise rotation of Victoria. Along the TRM segment and the oblique northern part of the Eastern Branch, rift-parallel motion is the largest, up to $26 \mathrm{~km}$ over $10 \mathrm{My}$.

Inclusion of the Tanzania craton that is partially traversed by the Eastern Branch prohibits substantial localization of the modeled Eastern Branch in the cratonic area (Fig. 6b), although increased strain rates are seen compared to the rest of the craton. Deformation is diverted around the eastern edge of the craton, and the maximum horizontal stress aligns with the craton edge. Increased transmission of plate motion to the microplate through the strong craton leads to higher angular velocities and a slight displacement of the pole to the east (Table 2). A similar effect is seen when the Turkana depression is included through a local thinning of the upper and lower crustal layers to 15 and $10 \mathrm{~km}$, respectively. The depression locally deflects the stress field to align with the depression, except in front of the Western Branch tip, where stress rotates to become orthogonal to the depression. Transmission of motion is larger in the north, bringing the larger rotation pole westward and closer to the microplate (Fig. $6 \mathrm{~g}$ ).

A gradient in the prescribed velocity (the domain-boundary orthogonal component of the velocity computed from the Nubia-Somalia Euler pole ${ }^{3}$; Table 1; Fig. 6d) to mimic the N-S relative velocity decrease of the Somalian plate (Fig. 1a) decreases the strain rate in the southern parts of the system. This prolongs the existence and extent of the strike-slip regime in the TRM segment and reduces the angular velocity. Due to the reduced velocity in the south, the addition of the strong Tanzania craton (Fig. 6d) affects the results less than in the case of uniform boundary conditions, although the pole varies less between 5 and $10 \mathrm{My}$. Together with the stronger Turkana depression (Fig. 6f), a
Victoria microplate rotation of $0.0708^{\circ} \mathrm{My}^{-1}$ around a pole at $(1165,3076) \mathrm{km}$ is found. This latter model, the most complex model, matches best with the most recent Victoria rotation ${ }^{3}$ of $0.0740^{\circ} \mathrm{My}^{-1}$ at $(1032,2837) \mathrm{km}$ in our coordinate system, as illustrated by Fig. $6 \mathrm{~g}$. All models with an EARS mobile belt configuration predict rotation poles that plot within the area spanned by geodetically derived Euler poles ${ }^{1,3,6}$.

In summary, our results show that with ongoing localization over time, the relative instantaneous rotation pole describing the microplate rotation moves closer to the microplate. Contemporaneously, the residuals in pole location decrease, signifying a more rigid behavior of the microplate. Larger extent of the preexisting weaknesses and a thicker microplate also increase the plate-like behavior. Only highly localized models have the instantaneous rotation pole at, or inside, the microplate boundaries; most of them lie less than $1000 \mathrm{~km}$ north of the microplate. Stresses in high-strain rate regions indicate tension and consequently normal faulting, except when the strength of the craton exceeds that of the major plates' lithosphere or under highly oblique, faster extension. In front of the rift tips, the maximum compressive stress aligns with the edges of the microplate. Despite the overall extensional setting, we find that rigid areas may exhibit strike-slip and even thrust-faulting regimes.

\section{Discussion}

We first discuss our generic model results in light of previous modeling studies. Then we examine our EARS-specific findings and their implications for our understanding (Fig. 7) of stress patterns and kinematics of the present-day EARS (Fig. 8). 
a

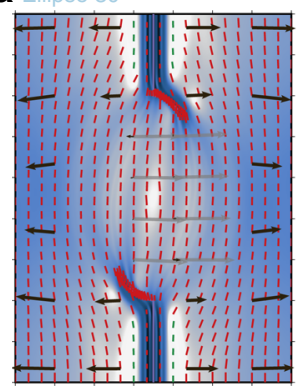

f Small circle $90^{\circ}$

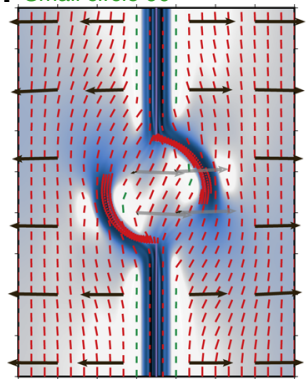

j Thick LAB seed

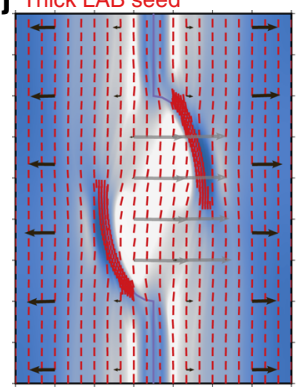

n

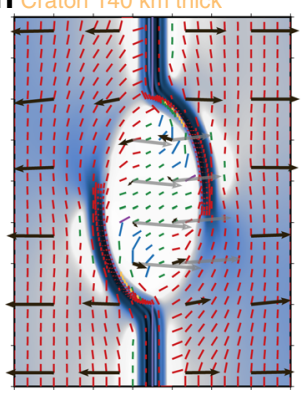

b

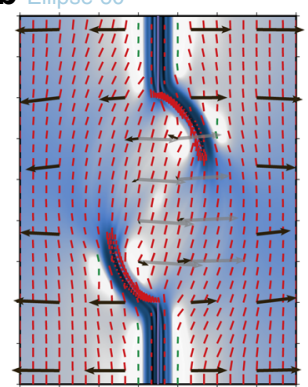

g

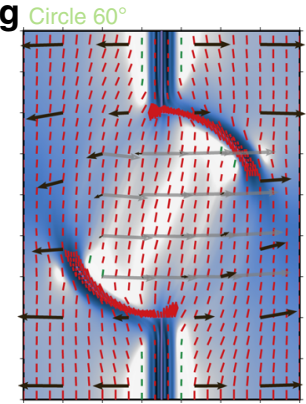

$\mathbf{k}$ Thin $L A B$ seed

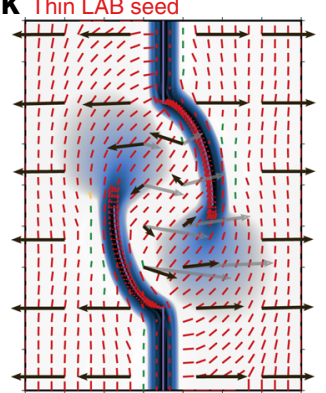

0

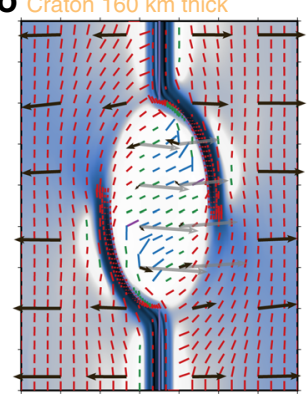

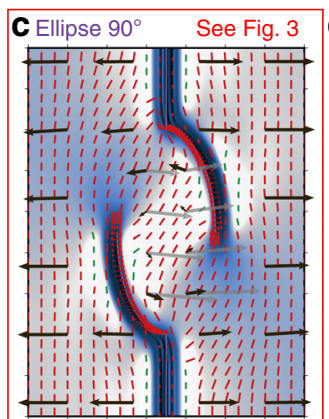

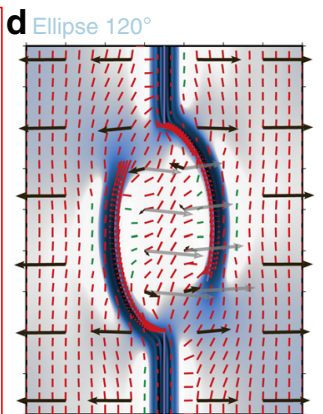

h

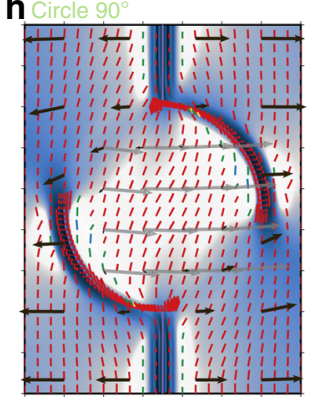

i

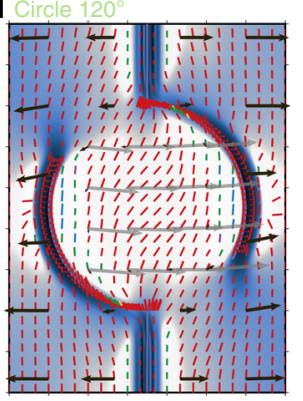

I Wide LAB seed

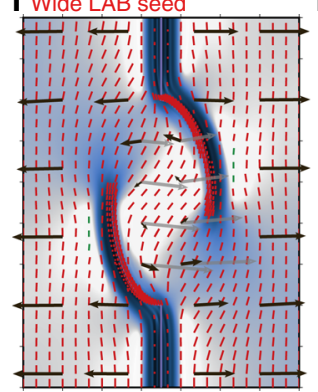

p

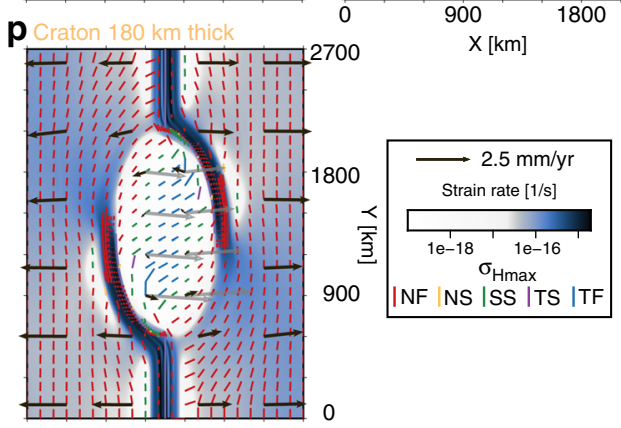

e

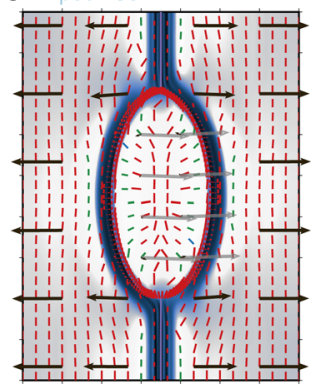

q

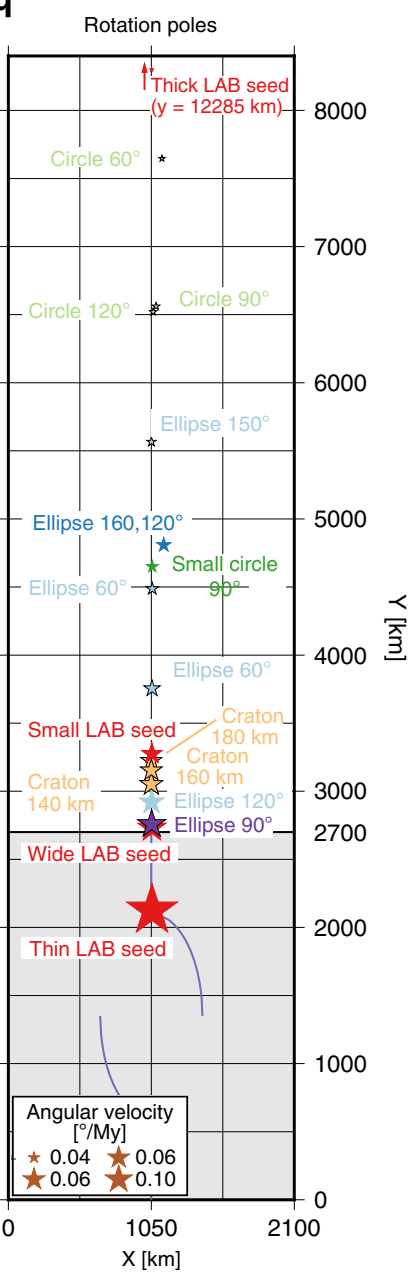

Fig. 4 Controlling factors of the generic mobile belt configuration model. Depicted are the strain rate field, maximum horizontal compressive stress $\sigma_{\text {Hmax }}$, and the velocity vectors at 3-km depth and $10 \mathrm{My}$ for the generic models in a-p, together with the respective microplate rotation poles relative to the western plate in $\mathbf{q}$. Black vectors in a-p are plotted in the model frame of motion, while the dark-gray vectors represent the microplate motion in a Nubiafixed frame. Black and gray vectors are scaled equally. A red box indicates the reference model detailed in Fig. 3. Details on each of the models are given in Table 1. NF normal faulting, NS normal and strike-slip faulting, SS strike-slip faulting, TS thrust and strike-slip faulting, TF thrust faulting.

The generic 3D numerical models presented demonstrate how a large continental microplate can rotate under homogeneous farfield extension through the edge-driven mechanism. This rotation is predominantly controlled by the length and obliquity of the stronger microplate edges where the motion of the major plates is transmitted to the microplate, that of the diverging segments facilitating the rotation, and the absolute distance between the segments.

Our models demonstrate that the edge-driven oceanic microplate model ${ }^{16}$ is also a valid driving mechanism for continental microplate rotation in the sense that the drag of the bounding plates generates the rotation. Similar to the oceanic microplate examples ${ }^{16}$, our relative instantaneous poles are not located at or even close to the rift tips, as suggested for the idealized edgedriven oceanic microplate model ${ }^{16}$. With the poles several hundred kilometers away from the Victoria microplate, this difference could indicate slip between the plates or a contribution from viscous coupling to mantle flow ${ }^{16}$. The orthogonal geometric relation between the line connecting the instantaneous rotation poles and the regional extension direction in the idealized edgedriven model ${ }^{16}$ also does not hold when the prescribed velocity varies along the model boundaries. 
Table 1 Predicted rotation poles relative to the western plate after $10 \mathrm{My}$ for different controlling parameters of the generic model setup.

\begin{tabular}{|c|c|c|c|c|c|c|c|c|c|c|c|}
\hline Ellipse $60^{\circ}$ & 60 & 375 & 750 & 675 & 0.8 & 50 & 120 & $(1055,3755)$ & 57 & 0.0597 & $4 b$ \\
\hline${ }^{\star}$ Ellipse $90^{\circ}$ & 90 & 375 & 750 & 675 & 0.8 & 50 & 120 & $(1053,2758)$ & 42 & 0.1021 & $4 c$ \\
\hline Ellipse $120^{\circ}$ & 120 & 375 & 750 & 675 & 0.8 & 50 & 120 & $(1051,2917)$ & 27 & 0.0914 & $4 d$ \\
\hline Circle $60^{\circ}$ & 60 & 750 & 750 & 300 & 0.8 & 50 & 120 & $(1128,7647)$ & 142 & 0.0228 & $4 g$ \\
\hline Circle $90^{\circ}$ & 90 & 750 & 750 & 300 & 0.8 & 50 & 120 & $(1085,6562)$ & 52 & 0.0276 & $4 \mathrm{~h}$ \\
\hline Circle $120^{\circ}$ & 120 & 750 & 750 & 300 & 0.8 & 50 & 120 & $(1063,6521)$ & 36 & 0.0277 & $4 i$ \\
\hline Ellipse $160,120^{\circ}$ & 160,120 & 375 & 750 & 675 & 0.8 & 50 & 120 & $(1141,4808)$ & 32 & 0.0523 & - \\
\hline Thick $L A B$ seed & 90 & 375 & 750 & 675 & 0.9 & 50 & 120 & $(1053,12285)$ & 64 & 0.0131 & $4 j$ \\
\hline Thin LAB seed & 90 & 375 & 750 & 675 & 0.7 & 50 & 120 & $(1055,2125)$ & 43 & 0.1871 & $4 k$ \\
\hline Wide $L A B$ seed & 90 & 375 & 750 & 675 & 0.8 & 75 & 120 & $(1054,2732)$ & 42 & 0.1041 & 41 \\
\hline
\end{tabular}

RMSD root-mean-square residual distance.

Italic values indicate the parameters varied with respect to the reference model Ellipse $90^{\circ}\left(^{*}\right)$

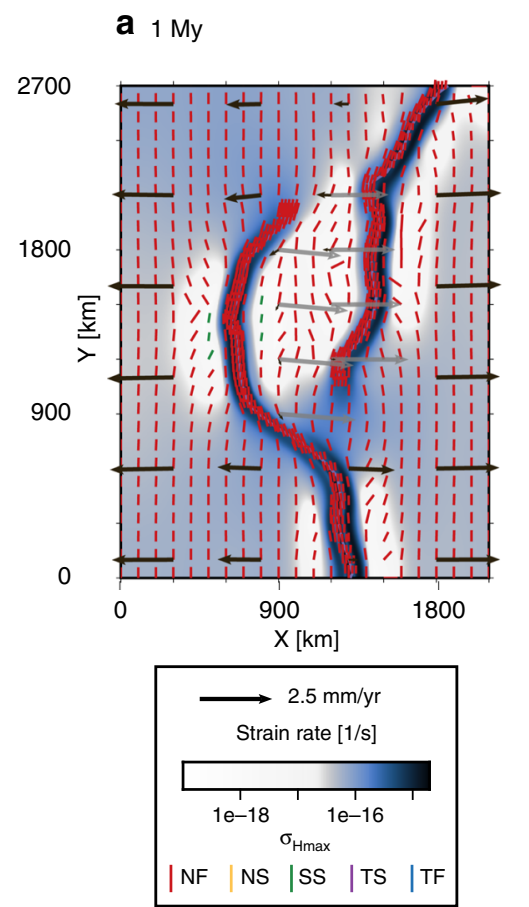

b 5 My

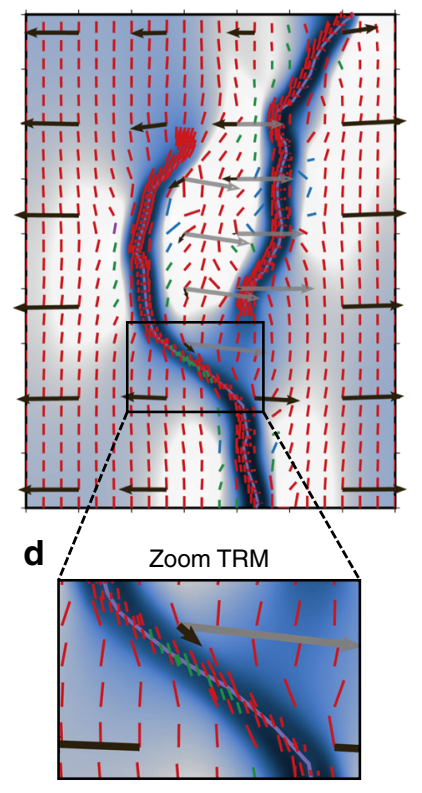

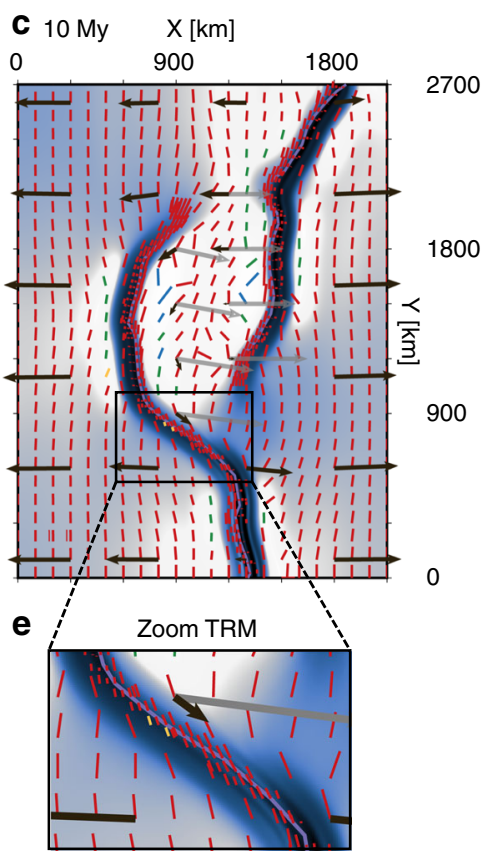

Fig. 5 East African Rift System-specific mobile belt configuration EARS model results. a-e Depicted are the strain rate field, maximum horizontal compressive stress $\sigma_{\mathrm{Hmax}}$ colored according to the tectonic stress regime, and the velocity vectors at 3-km depth for the East African Rift System initial mobile belt configuration at 1, 5, and $10 \mathrm{My}$. Black vectors are plotted in the model frame of motion, while the dark-gray vectors represent the microplate motion in a Nubia-fixed frame. Black and gray vectors are scaled equally. Panels $\mathbf{d}$ and $\mathbf{e}$ show a zoom-in of the oblique rift section in the boxed area indicated in $\mathbf{b}$ and $\mathbf{c}$, respectively. NF normal faulting, NS normal and strike-slip faulting, SS strike-slip faulting, TS thrust and strike-slip faulting, TF thrust faulting.

On a smaller scale than continental and oceanic microplates, microblock rotation due to drag of the bounding blocks was observed in $2 \mathrm{D}$ visco-elasto-plastic spring models ${ }^{17}$, in which $\sim 30-70 \mathrm{~km}$-sized microblocks were captured by offset fault segments and subsequently rotated with ongoing fault opening.
Comparable with our findings, the direction of rotation depended on the kinematics of the transfer zone: in the case of a rightlateral step, rotation was counterclockwise and vice versa.

The offset between interacting mid-oceanic ridge or continental rift segments has been shown to be a crucial component in the 
Table 2 Predicted rotation poles relative to Nubia at 5 and 10 My for different lithospheric strength configurations and prescribed extension velocities for the East African Rift System-specific mobile belt configuration model setup.

\begin{tabular}{|c|c|c|c|c|c|c|c|c|}
\hline Model name & $\begin{array}{l}\text { Time } \\
\text { [My] }\end{array}$ & $\begin{array}{l}v_{x}^{W}, v_{x}^{E} \\
{\left[\mathrm{~mm} \mathrm{yr}^{-1}\right]}\end{array}$ & $\begin{array}{l}\text { Tanzania craton } \\
\text { [km] }\end{array}$ & $\begin{array}{l}\text { Turkana depression } \\
\text { [km, km] }\end{array}$ & $\begin{array}{l}\text { Pole location } \\
\text { [km, km] }\end{array}$ & $\begin{array}{l}\text { RMSD } \\
{[\mathbf{k m}]}\end{array}$ & $\begin{array}{l}\text { Angular velocity } \\
{\left[\mathrm{My}^{-1}\right]}\end{array}$ & Fig. \\
\hline \multirow[t]{2}{*}{${ }^{\star}$ EARS } & 5 & $-2.5,2.5$ & 120 & 20,15 & $(1211,3148)$ & 4 & 0.0651 & \\
\hline & 10 & & & & $(1203,3197)$ & 4 & 0.0772 & $6 a$ \\
\hline Craton & 10 & & & & $(1244,3183)$ & 4 & 0.0964 & $6 b$ \\
\hline \multirow[t]{2}{*}{ Anza } & 5 & $-2.5,2.5$ & 120 & 15,10 & $(1166,3303)$ & 8 & 0.0698 & \\
\hline & 10 & & & & $(1178,2887)$ & 4 & 0.0866 & $6 c$ \\
\hline \multirow[t]{2}{*}{ N-S vel. craton } & 5 & $\pm \frac{v_{e}+\Omega\left(y-y_{c}\right)}{2000}$ & 140 & 20,15 & $(1176,3395)$ & 6 & 0.0643 & \\
\hline & 10 & & & & $(1190,3349)$ & 8 & 0.0637 & $6 e$ \\
\hline \multirow[t]{2}{*}{ N-S vel. craton Anza } & 5 & $\pm \frac{v_{e}+\Omega\left(y-y_{c}\right)}{2000}$ & 140 & 15,10 & $(1153,3233)$ & 6 & 0.0686 & \\
\hline & 10 & & & & $(1165,3076)$ & 5 & 0.0708 & $6 f$ \\
\hline
\end{tabular}

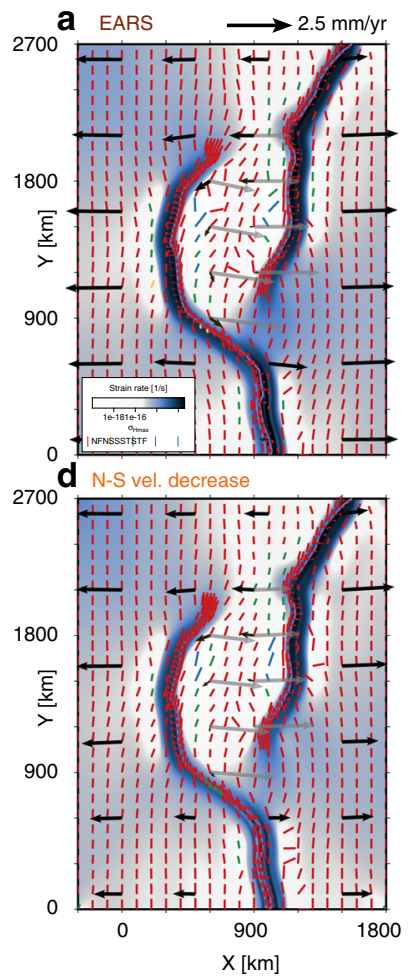

b
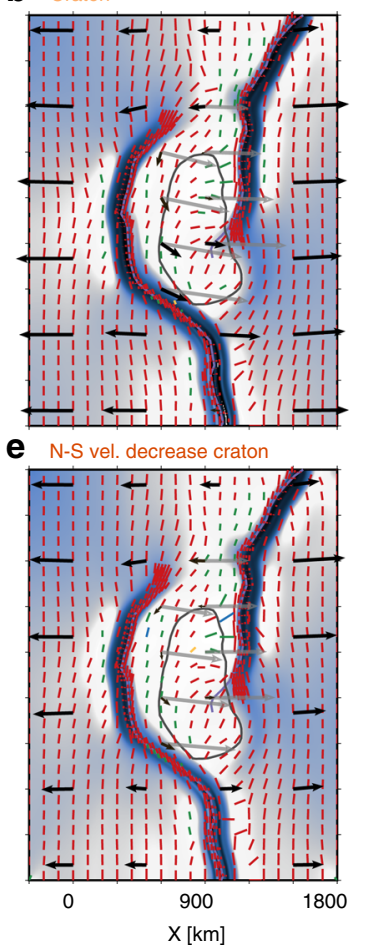

c

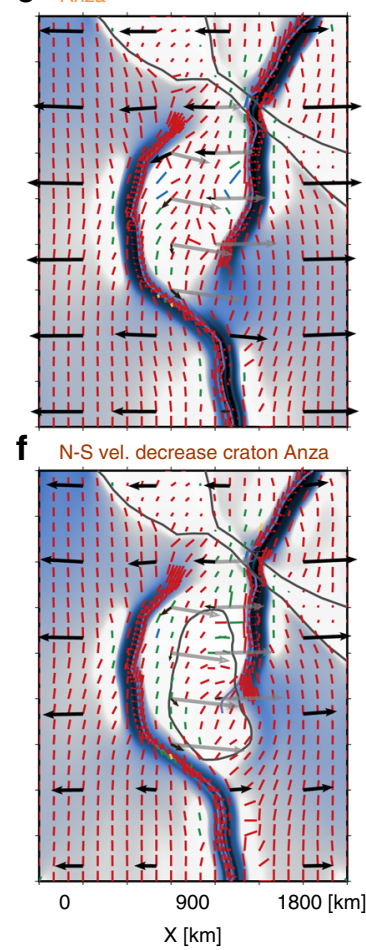

g

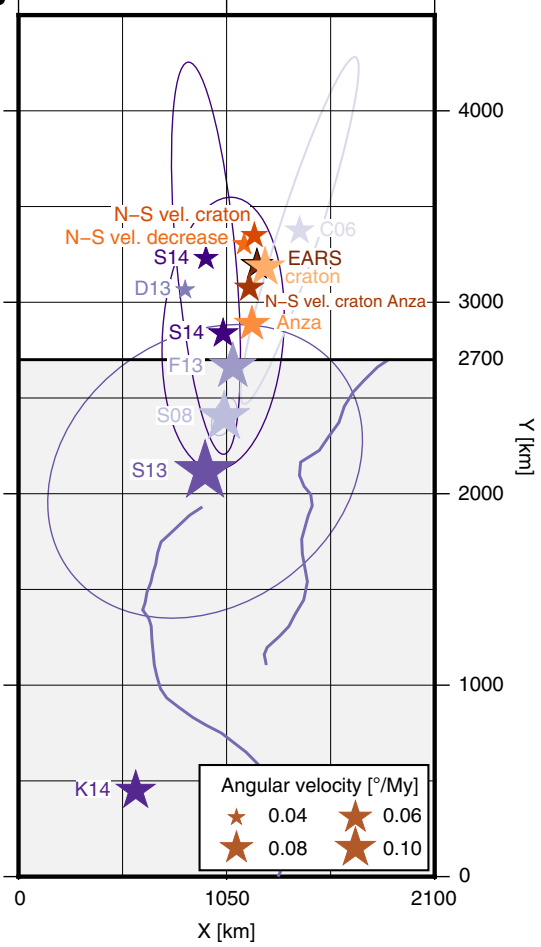

Fig. 6 Controlling factors of the East African Rift System-specific mobile belt configuration model. a-f Depicted are the strain rate field, maximum horizontal compressive stress $\sigma_{\mathrm{H} \max }$ colored according to the tectonic stress regime, and the velocity vectors at 3-km depth and $10 \mathrm{My}$ for the East African Rift System initial mobile belt configuration models. Black vectors are plotted in the model frame of motion, while the dark-gray vectors represent the microplate motion in a Nubia-fixed frame. Black and gray vectors are scaled equally. Tanzania craton and Turkana depression outlines are plotted in gray when used in the initial conditions. $\mathbf{g}$ In brown, the microplate rotation poles relative to the Nubian plate. Rotations poles from geodetic data inversion are included in purple, for references see the caption of Fig. 1a. The model domain is indicated in gray, and the mobile belt axes in purple. Details on each of the models are given in Table 2. NF normal faulting, NS normal and strike-slip faulting, SS strike-slip faulting, TS thrust and strike-slip faulting, TF thrust faulting.

formation of microplates. Through analog modeling, it was found that the ratio of the total length of the interacting segments to the initial offset determines whether a transform develops (for a small ratio) or an overlapping spreading center (OSC, for a large ratio), a precursor of oceanic microplate formation, is generated ${ }^{48}$. Crustal- scale 3D numerical models of continental rift interaction ${ }^{35}$ showed an overlapping, propagating, but non-linking mode for intermediate brittle-ductile coupling and larger offsets $(\geq 4$ times the upper crustal thickness). Growing rotating microplates between OSCs and nonrotating microplates between parallel ridges also 

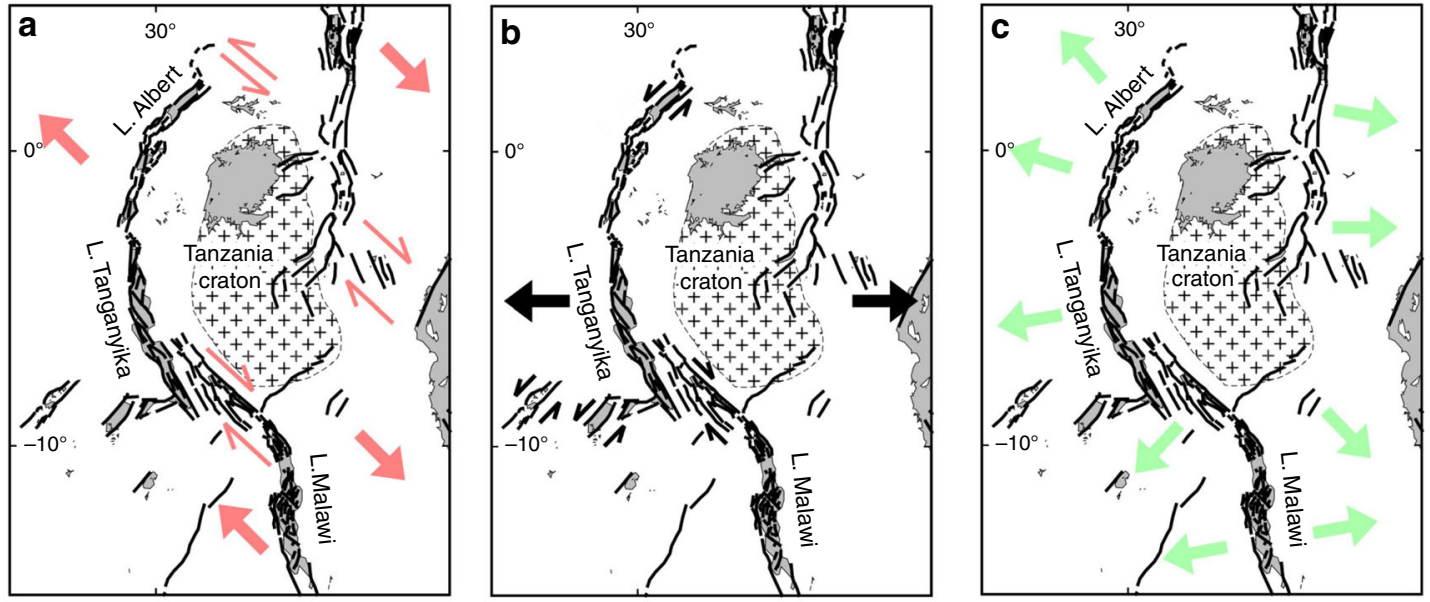

Fig. 7 Previously proposed kinematic opening models of the East African Rift System. a NW-SE regional extension with large strike-slip motion on NWstriking structures such as the Tanganyika-Rukwa-Malawi segment ${ }^{25}$. b Regional E-W extension leading to a minor strike-slip component on oblique segments $^{53}$. c Regional E-W extension with predominantly normal faulting suborthogonal to the rift segments ${ }^{54}$.

form in the crustal-scale models for large initial offsets $(\geq 60 \mathrm{~km})$ and slow-healing rates ${ }^{49}$. Similar kinematics are found for oblique pre-existing weak or strong regions: a northwest trending oblique rift seed and coupled crust and lithospheric mantle produced a counterclockwise rotating OSC in 3D numerical models ${ }^{36}$. In another numerical study ${ }^{32}$, counterclockwise rotating continental microplates formed in the case of left-laterally deflected propagating rifts as a consequence of an oblique, NW-trending strong inherited structure.

Based on the above modeling results of previous studies, it is evident that not only the segment offset, but also the strength and thickness of the lower crust, and thus the brittle-ductile/ crust-mantle coupling, are important factors in switching between different modes of interaction of extensional segments. We have not explored the space spanned by the rheological and crustal thickness parameters, but instead used standard flow law parameters and crustal thicknesses representative of the region. Only for the smallest extents of the mobile belts or a small perturbation of the LAB, the rifts fail to localize sufficiently or directly crosscut the would-be microplate (Fig. 4).

There is consensus on the relationship between the inherited weakness of the mobile belts and the location of the curved, overlapping EARS segments $21,23,39,50$. Other modeling studies $26,35,49,51,52$ have also shown that two overlapping rift segments can form without pre-existing strength heterogeneities like mobile belts (socalled soft linkage). These overlapping segments would again set the stage for the edge-driven mechanism to generate rotation of the encompassed microplate.

Our EARS-specific models provide a good fit with kinematic models from geodetic data inversion. Figure 8 a shows the predicted relative motion of the Victoria microplate and the Somalia plate w.r.t. their respective eastern neighbors. The southward, resp. northward, increase in extension velocity and higher relative velocities in the northeast versus southwest match the trends in the predicted plate motions ${ }^{3}$ plotted in Fig. $8 \mathrm{~b}$. Also, for a specific latitude, extension is not equally distributed between the Eastern and Western Branch ${ }^{1}$. As such, the rotation pole describing Victoria's predicted rotation $\left((1165,3076) \mathrm{km}\right.$ and $\left.0.0708^{\circ} \mathrm{My}^{-1}\right)$ fits the pole obtained from GNSS observations ${ }^{3}((1032,2837) \mathrm{km}$ and $\left.0.0740^{\circ} \mathrm{My}^{-1}\right)$ well within the confidence interval. Based on the generic modeling results, inclusion of the continuation of the Mozambique belt around the southeastern edge of Victoria (Fig. 1b), as well as variations in rift-normal extent of the belts, would probably improve the fit between our predicted pole and that found from block modeling.

Many authors investigating oceanic microplate rotation dismiss a mantle contribution to the rotation ${ }^{20}$ and even assign mantle drag to the resisting forces ${ }^{56}$. The Victoria microplate's counterclockwise motion has, in contrast, been suggested to derive from mantle flow interacting with the Tanzania craton's keel ${ }^{1,12,13}$. An earlier study ${ }^{1}$ argued that, since models of plume-craton interaction show focusing of mantle flow around the keel, and seismic anisotropy indicates NE-ward mantle flow underneath East Africa, this flow could act on the thickest, southern part of the Tanzania craton, inducing a rotation. However, the authors note that the WNW motion of Nubia predicted by the applied global hotspot frame does not match anisotropy directions, and thus, attribute these to plume-related flow. However, in more recent plate motion reference frames ${ }^{57}$, absolute Nubia plate motion is NNE (Fig. 1a), agreeing with the cited seismic anisotropy. Also, there is some disagreement on the distribution of low seismic velocity anomalies seen in the East African upper mantle. For example, whereas some studies ${ }^{58,59}$ advocate for one East African superplume, others ${ }^{60}$ distinguish separate lower and upper mantle plumes, or consider a lower mantle plume splitting in the upper mantle ${ }^{61}$, complicating the interpretation of seismic anisotropy in terms of plume-induced flow.

Plume-craton interaction has been extensively investigated $12,13,62,63$ with 3D upper mantle box models. Counterclockwise rotation of a central cratonic block was obtained in several model configurations $^{13}$, including models with a single-plume offset from the center and with two plumes impinging on the NE and SW corners of the craton. Localization of strain initially driven by the applied far-field extension was intensified by plume-related heat transport and channeling of plume material. The authors attribute the counterclockwise rotation to the distribution of plume forces interacting with the keel of the craton. At the same time, the plume head impingement in their models induces a configuration of strain localization and lithospheric weakness similar to our EARS models. It is hence not clear whether Victoria microplate rotation in their models is predominantly due to plume push or actually controlled by the edge-driven mechanism discussed above. This is not to say that plume-induced flow cannot contribute to microplate rotation; our models, notably those without a craton, however indicate that it is not required to generate such rotation. Numerical models ${ }^{64}$ did show that a plume will travel underneath the lithosphere to places of rheological contrast. Under slow extension, breakup occurred at the 
a

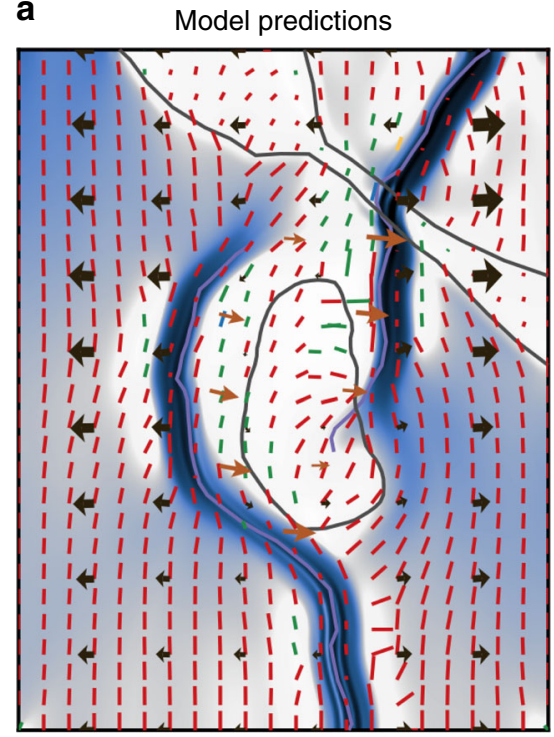

C WSM stress direction and regime

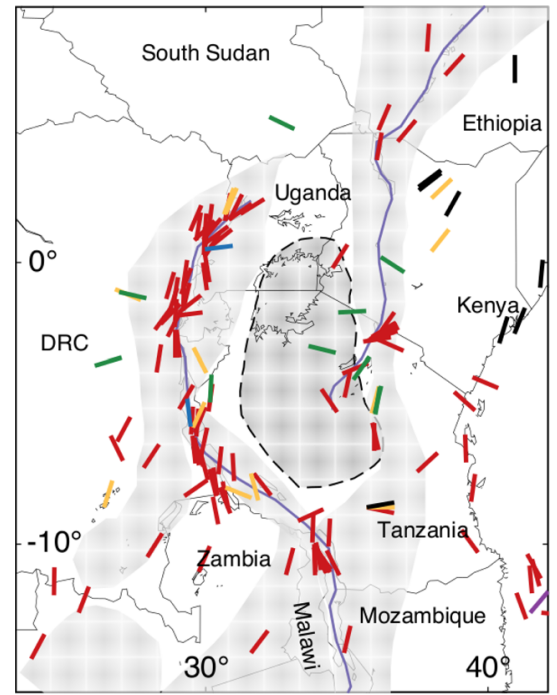

b GPS block model relative velocities

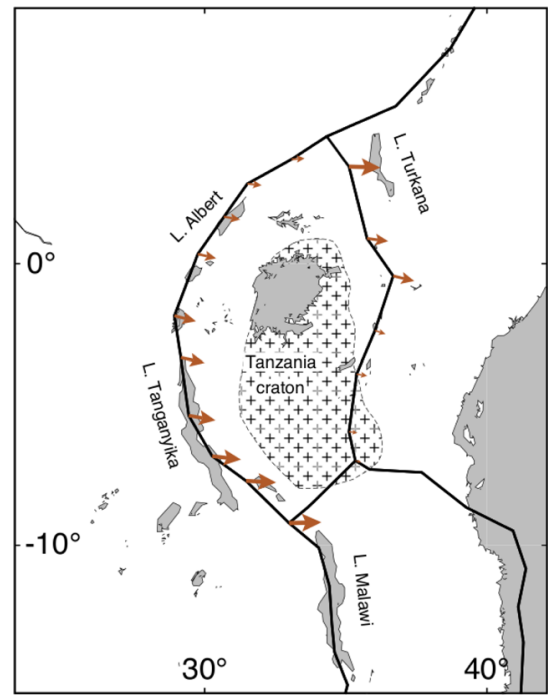

d Edge-driven microplate hypothesis

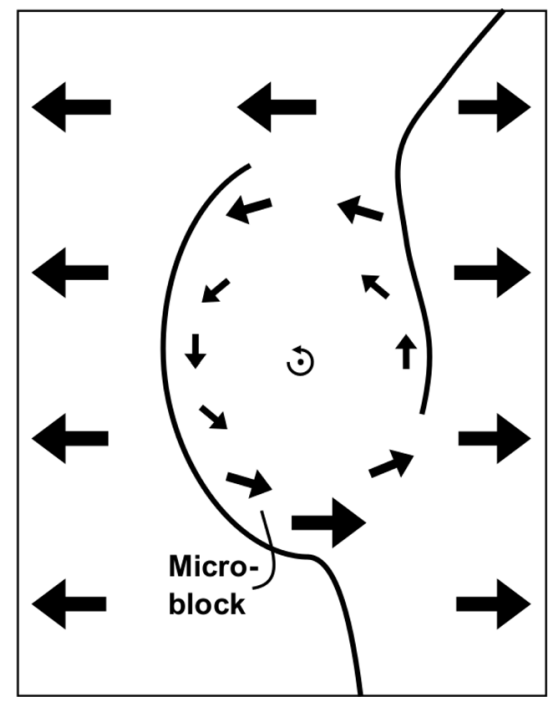

Fig. 8 Summary plot of East African Rift System modeling, data, and interpretation. a Results of model NS vel. craton Anza, including $\sigma_{\mathrm{Hmax}}$ and indicating in black the absolute velocity field and in orange the relative motion of Victoria with respect to the Nubia plate along the Western Branch (at $100 \mathrm{~km}$ from the original mobile belt axis) and the relative motion of the Somalia plate w.r.t. Victoria along the eastern plate boundary (as in panel b). b Kinematic block model prediction of Victoria microplate rotation ${ }^{3}$. Relative velocity vectors in orange represent the motion of the plate to the east of the plate boundary w.r.t. the plate to the west of the boundary. $\sigma_{\text {Hmax }}$ directions from the World Stress Map ${ }^{55}$ (WSM), including all data types and qualities, colored according to tectonic regime as in Figs. 3-6. Note that $\sigma_{\mathrm{Hmax}}$ bars of the WSM have a uniform length that does not represent their magnitude. d Our schematic representation of the edge-driven Victoria microplate rotation due to transmittance of the motion of the major plates.

rheological contrast. In that sense, the heterogeneity in the lithosphere due to the presence of mobile belts in the EARS could attract a plume that will heat and raise the LAB, while both the heterogeneity and the plume help to localize the deformation. Therefore, whether crustal/lithospheric heterogeneity initially localizes deformation and attracts a plume, or lithospheric heterogeneity in itself is enough to localize deformation (as in this study), the basic requirement is still lithospheric heterogeneity under far-field extension.

Our EARS model that best matches geodetic constraints provides stress predictions at the large and intermediate scale that we can compare with observations of the present-day and paleo stress field. Figure 8a and c juxtaposes the present-day maximum horizontal stress directions of model N-S vel. craton Anza and the World Stress $\mathrm{Map}^{55}$ (WSM). In general, our predicted stress orientations agree well with the WSM: predominantly normal faulting regimes are seen that rotate along the curved Western Branch, but are directed at an angle to the rift trend in the more oblique sections. However, we do not reproduce the more E-Woriented normal faulting seen in the Western Branch around a latitude of $-3^{\circ} \mathrm{N}$. WSM data in the Rukwa rift area are scarce, but some oblique normal faulting is documented and compares very well to our model predictions. Inside the microplate, in the more rigid domains, we obtain a good match with $\sigma_{\mathrm{Hmax}}$ in strike-slip mode trending NNE along the Western Branch and E-W along the Eastern Branch. Also, the rotation of $\sigma_{\mathrm{Hmax}}$ west of the Tanzania divergence matches well.

The few occurrences of tectonic stress regimes not conducive to normal faulting seen in the WSM were also found through processing of focal mechanisms ${ }^{65}$, with strike-slip regimes speckled 
around the Western and Eastern Branches. The obtained box averages, however, only leave normal-to-oblique normal slip regimes, with the exception of strike-slip in the Mbeya area between Lakes Rukwa and Malawi. Focal mechanisms are local indicators of the stress field that can be affected by higher-order stress sources. For example, stress can locally be deflected by oblique fabrics, such as the foliation in the Ubende belt. This hypothesis was put forward for the Rukwa rift $^{53}$ : the strength anisotropy deriving from the foliation reorients the stress field such that the oblique rift does not exhibit the predicted oblique slip, but pure normal faulting. Analog modeling studies ${ }^{66,67}$ even show stress reorientation along single faults within an oblique rift segment. Since our initial model conditions cannot take into account small-scale fabric trends such as foliation, nor can we examine our results at individual-fault scale, it is not surprising that we do not obtain the small-scale stress variations obtained from in situ measurements. One important observation from our models is, however, that the regional $\sigma_{\mathrm{Hmax}}$ does not need to be oriented orthogonally to the velocity nor to the relative velocity, or parallel to the rift trend. Hence, direct comparison of kinematic models and stress indicators is not warranted. For example, good agreement in direction $\left(\leq 20^{\circ}\right)$ between model velocities from GNSS stations ${ }^{6}$ and focal mechanisms ${ }^{65}$ was found in the Albertine, Kivu, and northern Tanganyika rifts (Fig. 1b), but large deviations along the southern Tanganyika and Rukwa rifts ${ }^{6}$. This disagreement between velocity and stress directions is clearly demonstrated in our modeling (Fig. 8) and, as such, a mismatch between kinematic and stress directions does not mean the kinematic model fails to describe the deformation of the system under investigation.

The opening kinematics of the fault segments along the EARS branches have been the topic of a long-standing debate that can be represented by three kinematic models: based on the arcuate shape of specifically the Western Branch and local kinematic indicators, the EARS was initially interpreted as a strike-slip system with a relative NW-SE extension direction ${ }^{25,68-71}$ implying large strike-slip motion especially on the TRM and Aswa segments (Fig. 7a). In a second view, the EARS is considered an extensional system resulting from relative $\mathrm{E}-\mathrm{W}$ regional extension, where the strike of obliquely oriented rift segments was guided by pre-existing fabrics of mobile belts ${ }^{53,72-77}$. In this view, oblique rifts like the TRM segment (Fig. 1b) are also expected to experience some degree of strike-slip motion (Fig. 7b). More recently, a modified version of this model was put forward ${ }^{54,65}$, in which deformation is purely extensional and orthogonal to the rift segments, including the TRM segment (Fig. 7c). This last opening model is informed by numerous available focal mechanisms indicating normal faulting that have been collected since the earlier models were suggested. As mentioned by these authors, the stress field may have changed over time, complicating the interpretation of fault-slip measurements in terms of regional extension direction. For example, quaternary clockwise rotations of the extension direction from ENE-WNW to NW-SE were inferred in the central Kenya rift $^{78}$ and the Malawi rift $^{79,80}$

Based on present-day and inferred past regional extension directions and our model results, we can synthesize the three EARS opening models presented in Fig. 7. In an overall E-W- extending system of partly overlapping arcuate rift branches ${ }^{53,72-77}$, our edgedriven microplate model intrinsically leads to local WNW-ESE extension directions ${ }^{25,68-71}$. In the oblique rift sections, normal faulting thus occurs at a small angle to the trend of the rift and preexisting weaknesses with few strike-slip occurrences (e.g., Fig. 8b; ref. ${ }^{65}$ ). Nevertheless, the rift-parallel and -orthogonal motion is predominantly accommodated by normal faulting ${ }^{54,65,81}$. Smallscale sources such as basement fabric locally deflect the stress field such that even the nonoverlapping, oblique TRM section deforms under a mostly normal-faulting regime ${ }^{53}$.
In conclusion, our suite of generic models demonstrates that the spatial distribution of lithospheric weakness (i.e., extent and distance) exerts a first-order control on microplate rotation. The strength (i.e., thickness) of the microplate and the geometry of the weak zones in the plane orthogonal to the rift axis are only of second-order control. For model geometries with right-lateral rift branch stepovers, we find a counterclockwise rotation of the microplate, which generates a clockwise shift of the local extension direction along the overlapping rift branches.

Moreover, we provide a mechanical explanation for the counterclockwise rotation of the continental Victoria microplate in the Nubia-Somalia divergent plate boundary. The edge-driven rotation stems from shear of the major plates along the northwest and southeast corners of the microplate, where both a strong failed rift and cratonic lithosphere transmit this motion and divert propagation of the rift branches surrounding the Victoria microplate. These overlapping rift branches following the weak Proterozoic suture zones around the craton facilitate the rotation. Under regional $\sim \mathrm{E}-\mathrm{W}$ extension, this modeled rotation results in local extension directions that strike more WNW-ESE. Together with the oblique orientation of the pre-existing weaknesses, the rotation leads to predominantly normal faulting oblique to the regional and local extension direction. In the most oblique $\left(\sim 45^{\circ}\right)$ section of the Western Branch, the Tanganyika-Rukwa-Malawi segment, the rotation can produce transient strike-slip faulting, although comparison to stress observations suggests a local stress reorientation, possibly due to inherited mechanical anisotropy.

\section{Methods}

Governing equations. We use the open-source, massively parallel, finite-element code ASPECT ${ }^{41-44}$ to solve the extended Boussinesq equations of momentum, mass, and energy (assuming an infinite Prandtl number) combined with advection equations for each Eulerian compositional field $c_{i}$

$$
\begin{gathered}
-\nabla \cdot(2 \eta \dot{\epsilon})+\nabla P=\rho \mathbf{g} \\
\nabla \cdot \mathbf{v}=0 \\
\bar{\rho} c_{P}\left(\frac{\partial T}{\partial t}+\mathbf{v} \cdot \nabla T\right)-\nabla \cdot(k+\nu) \nabla T=\bar{\rho} H \\
+2 \eta \dot{\epsilon}: \dot{\epsilon} \\
+\alpha T(\mathbf{v} \cdot \nabla P) \\
\frac{\partial c_{i}}{\partial t}+\mathbf{v} \cdot \nabla c_{i}-\nabla \cdot \nu \nabla c_{i}=0
\end{gathered}
$$

where $\dot{\epsilon}$ is the deviator of the strain rate tensor $\frac{1}{2}\left(\nabla \mathbf{v}+(\nabla \mathbf{v})^{T}\right)$, density $\rho=$ $\rho_{0}(1-\alpha(T-\bar{T}))$ with $\bar{T}$ the adiabatic reference temperature, $\bar{\rho}$ is the adiabatic reference density, and $v$ is the artificial diffusion. All other symbols are defined in Supplementary Table 1 .

Model domain. The governing equations are solved on a rectangular cuboid domain of 2100-km length in the $x$-direction and $y$ - and $z$-dimensions of 2700 and $300 \mathrm{~km}$, respectively (see outline in Fig. 1a and the actual domain in Fig. 2).

The domain is at start-up variably discretized in depth, leading to a lithospheric resolution of $9.375 \mathrm{~km}$, while below $160-\mathrm{km}$ depth, resolution is $18.75 \mathrm{~km}$. The mesh resolution is kept constant over time, while mesh nodes can be displaced vertically in response to the free surface. For optimal use of the second-order finite elements, visualization of the solution is performed on a mesh of twice this resolution. Each model run requires about $8 \mathrm{~h}$ of run time using 800 processes.

Initial conditions. The model domain is filled with four compositional layersupper crust, lower crust, mantle lithosphere, and sublithospheric mantle-that are individually perturbed to initiate rifting or to create areas of different rheological strength (e.g., representing the thick, strong Tanzania craton or the weak mobile belts). The reference Moho is set at $35 \mathrm{~km}$, which lies within the inferred range of our study area ${ }^{83,84}$. We choose the unperturbed Lithosphere-Asthenosphere Boundary (LAB) to lie at $120-\mathrm{km}$ depth, loosely based on several lithospheric thickness maps ${ }^{84}$ and within the range of the global thermal model $\mathrm{TC1}^{85}$. The initial temperature distribution in the lithosphere follows a steady-state geotherm ${ }^{86}$ that considers the local thickness of the compositional layers and their material properties (i.e., density, thermal conductivity, and radioactive heating) along $1 \mathrm{D}$ depth profiles (i.e., solutions of $T^{\prime \prime}(d)=-\frac{H}{k}$ ). The LAB is defined as a specific 
isotherm $(1576 \mathrm{~K})$, below which a mantle adiabat $\left(T_{a}^{\prime}(d)=\frac{\alpha|g| T}{C_{p}}\right)$ is assumed. The resulting surface heat flow $\left(58-66 \mathrm{~mW} \mathrm{~m}^{-2}\right.$ for model real N-S vel. decrease craton Anza at start-up) matches the overall magnitudes and trends of heat flow measurements $\left(15-75 \mathrm{~mW} \mathrm{~m}^{-2}\right)$ and predictions $\left(20-185 \mathrm{~mW} \mathrm{~m}^{-2}\right)^{87}$.

Present-day data point to mobile belts as regions of smaller thermal ${ }^{85}$ and elastic $^{88}$ thickness where strain localizes during the supercontinent cycle ${ }^{89}$. LPOinduced mechanical anisotropy of the lithospheric mantle could also contribute to the preferred reactivation of these highly deformed belts ${ }^{37}$. We capture all possible sources of the weakness of mobile belts (e.g., foliation and higher temperatures) and/or the impingement of plume material at such strength contrasts ${ }^{64}$ by representing the mobile belts through perturbations of the LAB, mimicking a small amount of lithospheric thinning. The perturbations are specified through a Gaussian distribution of thinning factor $f$ around line segments representing the belt axes (see Fig. 2 for the definition of parameters $f, \alpha, a$, and $b$ that define the mobile belt geometry). Under the assumption of thermal steady state, the thinner mantle lithosphere in the belts leads to higher temperatures in the lithosphere, which in turn decrease its strength (compare the first two strength profiles in Fig. 2). The integrated strength in the mobile belts is $5.1 \mathrm{TN} \mathrm{m}^{-1}$, which is in line with the estimates ${ }^{90}$ of $3-5 \mathrm{TN} \mathrm{m}^{-1}$ for the force available for general continental extension.

The more complex EARS-specific models include mobile belt and Turkana depression geometries that are digitized from Fig. $1 \mathrm{~b}$ and a digitized thicker cratonic area ${ }^{59}$. The transition to thicker or thinner areas is smoothed by a hyperbolic tangent with a half-width of $25 \mathrm{~km}$.

Rheology. Our description of the rheological model used to compute effective viscosity $\eta$ in Eq. (1) consists of a viscoplastic rheology that combines the composite contributions of diffusion and dislocation creep with Drucker-Prager plasticity ${ }^{91}$. In addition, we include linear strain weakening of the internal angles of friction.

Diffusion and dislocation creep are formulated as ${ }^{92}$

$$
\eta_{\text {eff }}^{\text {diff } \mid \text { disl }}=\frac{1}{2}\left(\frac{1}{A}\right)^{1 / n} \dot{\epsilon}_{e}^{(1-n) / n} \exp \left(\frac{Q+P V}{n R T}\right),
$$

where in the case of diffusion creep, $n=1$, while for dislocation creep $n>1$. The effective deviatoric strain rate is defined as $\dot{\epsilon}_{e}=\sqrt{\frac{1}{2} \dot{\epsilon}_{i j}^{\prime} \dot{\epsilon}_{i j}^{\prime}}$. See Supplementary Table 1 for the definition and values of other symbols; the upper crust follows a wet quartzite rheological law ${ }^{93}$, the lower crust is described by wet anorthite ${ }^{94}$, while all mantle material behaves like dry olivine ${ }^{95}$.

Plastic yielding is implemented by locally rescaling the effective viscosity in such a way that the stress remains on the yield envelope ${ }^{96}$, with the effective plastic viscosity given by

$$
\eta_{\mathrm{eff}}^{\mathrm{pl}}=\frac{\frac{6 C \cos \phi}{\sqrt{3}(3+\sin \phi)}+\frac{6 P \sin \phi}{\sqrt{3}(3+\sin \phi)}}{2 \dot{\epsilon}_{e}} .
$$

The internal angle of friction $\phi$ is linearly weakened from $20^{\circ}$ to $5^{\circ}$ on the accumulated plastic strain $\epsilon$ interval $[0.0,0.5]^{51,97,98}$. Plastic strain is tracked on a compositional field as

$$
\phi_{\text {weakened }}=\phi+\left(\phi-\phi \cdot \phi_{\mathrm{wf}}\right)\left(\frac{\min \left(\max \left(\epsilon, \epsilon_{\min }\right), \epsilon_{\max }\right)-\epsilon_{\min }}{\epsilon_{\min }-\epsilon_{\max }}\right) .
$$

The resulting nonlinearities in the Stokes equations introduced by the viscoplastic rheology are iterated out using Picard iterations ${ }^{99}$.

Boundary conditions. We use prescribed velocities representing far-field plate motions on the western and eastern boundaries to enforce rifting over time. As demonstrated by the evolving views on EARS development ${ }^{9,74,100,101}$, the timing of initiation and propagation of the eastern and western rift branches is complex. Nevertheless, there is general agreement that rifting was established in both branches by $\sim 10 \mathrm{Ma}^{10,101,102}$.

From geodetic and geological data inversion, the present-day Somalia-Nubia plate system relative extension direction is $\sim \mathrm{E}-\mathrm{W}$, as plotted in Fig. la along the eastern model domain boundary, and thus derived extension rates along the EARS reach up to $5.2 \pm 0.9 \mathrm{~mm} \mathrm{yr}^{-1}$, with earlier studies predicting up to $7.2 \mathrm{~mm} \mathrm{yr}^{-13}$. Good agreement is reached between this present-day motion and predictions from oceanic paleomagnetic data for the last 3.2 $\mathrm{My}^{2,103}$. A slowdown of Somalia-Nubia motion occurred around $11 \mathrm{Ma}$, but since then spreading velocities have been relatively stable, between 3.7 and $5.0 \mathrm{~mm} \mathrm{yr}^{-1}$ with an azimuth of $80-120^{\circ}$ for a point at $35.2^{\circ} \mathrm{E},-18^{\circ} \mathrm{N}^{104}$. From Southwest Indian Ridge reconstructions, stable rift-normal extension has been found to occur since $5.2 \mathrm{Ma}$ at $40^{\circ} \mathrm{E}, 9^{\circ} \mathrm{N}$, concurrent with present-day motions ${ }^{105}$. Between 5.2 and $11 \mathrm{Ma}$, extension might have been slower, with velocities varying between 2.4 and $5.12 \mathrm{~mm} \mathrm{yr}^{-1}$ over the last $11 \mathrm{My}$, and the extension direction between 105 and $125^{\circ}$ from north.

Based on the above, we simplify our extensional boundary conditions to orthogonal, constant velocities 32,63 , applied such that the material is moving outward with a velocity of $v_{x}=\frac{1}{2} \cdot 5 \mathrm{~mm} \mathrm{yr}^{-1}$ on the right and left boundary (the tangential velocity components are left free). This outflow is compensated by inflow of an equal volume of material through the bottom boundary, and the front and back boundaries feature free slip. The top boundary is a true free surface to allow for the formation of topography in response to the internal stress state. Note that as we ignore the much smaller boundary-parallel component $\left(\sim 0.5 \mathrm{~mm} \mathrm{yr}^{-1}\right)$, in some places, this might reduce the obliquity of the extension direction, while increasing it in others. As oblique extension has been suggested to be more efficient ${ }^{106}$, this could change the localization of deformation and, in turn, the microplate rotation. Neglecting the small $(\leq 20 \%)$ temporal changes in extension direction as suggested by plate reconstructions ${ }^{104,105}$ might similarly change the present-day velocity prediction.

Post processing. To quantify our model results, we compute the rotation pole of the microplate between the eastern and western rift branches relative to the western (Nubian) plate. This is done by querying the finite-element solution for the velocity values at $3-\mathrm{km}$ depth (w.r.t to the initial unperturbed surface) on a regularly spaced grid covering the entire domain and a more refined grid around the rift. For all points falling within the area spanned by the original mobile belt segments (up to a $100-\mathrm{km}$ distance to these segments), we then invert for the Euler pole by first subtracting the rotation's pivot point obtained through the least-squares method from all velocity point coordinates and then solving $\mathbf{v}=A \boldsymbol{\Omega}$, where $\mathbf{v}$ are the relative velocity vectors and $\boldsymbol{\Omega}$ is the rotation vector ${ }^{1}$. An estimate of the confidence of the location of the pivot point and thus of the rigidity of the microplate is obtained from the root-mean-square residual distance (RMSD) between the point and the lines normal to the velocities. In comparing our model poles with those found from data inversion, it is important to remember that the inversion of GNSS data, earthquake slip vectors, and geologic indicators assumes that the plates are rigid blocks, with only some studies $^{3}$ accounting for elastic strain accumulating on plate-boundary faults. Our models, however, do not include elastic deformation, but do allow for internal deformation of the plates.

On the same regular grid, we also compute the maximum horizontal compressive stress $\sigma_{\mathrm{Hmax}}$ and the tectonic regime (normal faulting NF, normal faulting with a strike-slip component NS, strike-slip faulting SS, thrust faulting with a strike-slip component TS, or thrust faulting TF) from the plunges of the compressive stress eigenvectors ${ }^{107}$. Note that this is the convention used in the World Stress Map Project ${ }^{55}$. We further track the displacement along the rift segments with passive particles advected with the flow. Initially, these particles are distributed in pairs along the rift on opposing sides and at $200-\mathrm{km}$ distance of the mobile belt axis. After $10 \mathrm{My}$ of model time, we decompose the pairwise relative motion vector into a rift-parallel and -normal component.

\section{Data availability}

The input files to reproduce the data that support the findings in this study have been deposited in the GitHub repository https://github.com/anne-glerum/paper-Victoriamicroplate-rotation.

\section{Code availability}

The modeling software ASPECT can be obtained from GitHub at https://github.com/ geodynamics/aspect; in this study, a modification of a 2.1.0-predeveloper version was used (commit 31a88da) that can be obtained from https://github.com/anne-glerum/ aspect/tree/paper-Victoria-microplate-rotation. The repository https://github.com/anneglerum/paper-Victoria-microplate-rotation contains the input files to reproduce the model results, as well as information on the versions of the libraries underlying the ASPECT installation.

Received: 31 August 2019; Accepted: 9 April 2020; Published online: 08 June 2020

\section{References}

1. Calais, E., Ebinger, C., Hartnady, C. \& Nocquet, J. Kinematics of the East African Rift from GPS and earthquake slip vector data. Geol. Soc., London, Special Publications 259, 9-22 (2006).

2. Stamps, D. S. et al. A kinematic model for the East African Rift. Geophys. Res. Lett. 35, 32781 (2008).

3. Saria, E., Calais, E., Stamps, D. S., Delvaux, D. \& Hartnady, C. J. H. Presentday kinematics of the East African Rift. J. Geophys. Res.: Solid Earth 119, 3584-3600 (2014).

4. Déprez, A., Doubre, C., Masson, F. \& Ulrich, P. Seismic and aseismic deformation along the East African Rift System from a reanalysis of the GPS velocity field of Africa. Geophys. J. Int. 193, 1353-1369 (2013).

5. Saria, E., Calais, E., Altamimi, Z., Willis, P. \& Farah, H. A new velocity field for Africa from combined GPS and DORIS space geodetic solutions: contribution to the definition of the African reference frame (AFREF). J. Geophys. Res.: Solid Earth 118, 1677-1697 (2013). 
6. Fernandes, R. M. S., Miranda, J. M., Delvaux, D., Stamps, D. S. \& Saria, E. Reevaluation of the kinematics of Victoria Block using continuous GNSS data. Geophys. J. Int. 193, 1-10 (2013).

7. Kreemer, C., Blewitt, G. \& Klein, E. C. A geodetic plate motion and global strain rate model. Geochem., Geophys., Geosyst. 15, 3849-3889 (2014).

8. Paul, H. Global Earthquake Model Foundation-OpenQuake Platformgem_active_faults. Online database. https://platform.openquake.org/layers/ oqplatform:gem_active_faults (2017).

9. Nyblade, A. A. \& Brazier, R. A. Precambrian lithospheric controls on the development of the East African rift system. Geology 30, 755-758 (2002).

10. Ring, U. The East African Rift system. Austrian J. Earth Sci. 107/1, 132-146 (2014).

11. Amante, C. \& Eakins, B. W. ETOPO1 1 Arc-minute global relief model: procedures, data sources and analysis. NOAA Technical Memorandum NESDIS NGDC-24. https://doi.org/10.7289/V5C8276M (National Geophysical Data Center, NOAA, 2009).

12. Koptev, A., Calais, E., Burov, E., Leroy, S. \& Gerya, T. Dual continental rift systems generated by plume-lithosphere interaction. Nat. Geosci. 8, 388-392 (2015).

13. Koptev, A. et al. Contrasted continental rifting via plume-craton interaction: applications to central East African Rift. Geosci. Front. 7, 221-236 (2016)

14. Stamps, D. S., Flesch, L. M., Calais, E. \& Ghosh, A. Current kinematics and dynamics of Africa and the East African Rift system. J. Geophys. Res.: Solid Earth 119, 5161-5186 (2014).

15. Stamps, D. S., Iaffaldano, G. \& Calais, E. Role of mantle flow in Nubia-Somalia plate divergence. Geophys. Res. Lett. 42, 290-296 (2015).

16. Schouten, H., Klitgord, K. D. \& Gallo, D. G. Edge-driven microplate kinematics. J. Geophys. Res. 98, 6689-6701 (1993).

17. Koehn, D., Aanyu, K., Haines, S. \& Sachau, T. Rift nucleation, rift propagation and the creation of basement micro-plates within active rifts. Tectonophysics 458, 105-116 (2008).

18. Keary, P., Klepeis, K. A. \& Vine, F. J. Global Tectonics (John Wiley \& Sons, Ltd, 2009).

19. Hey, R. Tectonics / propagating rifts and microplates at mid-ocean ridges. in Encyclopedia of Geology (eds Selley, R. C., Cocks, L. R. M. \& Plimer, I. R.) 396-405 (Elsevier, Oxford, 2005).

20. Katz, R. F., Ragnarsson, R. \& Bodenschatz, E. Tectonic microplates in a wax model of sea-floor spreading. New J. Phys. 7, 37 (2005).

21. Daly, M. C., Chorowicz, J. \& Fairhead, J. D. Rift basin evolution in Africa: the influence of reactivated steep basement shear zones. in Inversion Tectonics (eds Cooper, M. A. \& Williams, G. D.) Vol. 44, 309-334 (Geological Society Special Publications, 1989).

22. Versfelt, J. \& Rosendahl, B. R. Relationships between pre-rift structure and rift architecture in Lakes Tanganyika and Malawi, East Africa. Nature 337, 354-357 (1989).

23. Smith, M. \& Mosley, P. Crustal heterogeneity and basement influence on the development of the Kenya Rift, East Africa. Tectonics 12, 591-606 (1993).

24. Hetzel, R. \& Strecker, M. Late Mozambique Belt structures in western Kenya and their influence on the evolution of the Cenozoic Kenya Rift. J. Struct. Geol. 16, 189-201 (1994).

25. Chorowicz, J. The East African rift system. J. African Earth Sci. 43, 379-410 (2005).

26. Le Gall, B. et al. Rift propagation at craton margin. Distribution of faulting and volcanism in the North Tanzanian Divergence (East Africa) during Neogene times. Tectonophysics 448, 1-19 (2008).

27. Katumwehe, A. B., Abdelsalam, M. G. \& Atekwana, E. A. The role of preexisting Precambrian structures in rift evolution: the Albertine and Rhino grabens, Uganda. Tectonophysics 646, 117-129 (2015).

28. Ebinger, C. J. et al. Rift deflection, migration, and propagation: Linkage of the Ethiopian and Eastern rifts, Africa. GSA Bull. 112, 163 (2000).

29. Boone, S. C. et al. Tectono-thermal evolution of a long-lived segment of the East African Rift system: thermochronological insight from the North Lokichar Basin, Turkana, Kenya. Tectonophysics 744, 23-46 (2018).

30. Bosworth, W. \& Morley, C. K. Structural and stratigraphic evolution of the Anza rift, Kenya. Tectonophysics 236, 93-115 (1994).

31. Benoit, M. H., Nyblade, A. A. \& Pasyanos, M. E. Crustal thinning between the Ethiopian and East African Plateaus from modeling Rayleigh wave dispersion. Geophys. Res. Lett. 33, 25687 (2006).

32. Brune, S., Corti, G. \& Ranalli, G. Controls of inherited lithospheric heterogeneity on rift linkage: numerical and analog models of interaction between the Kenyan and Ethiopian rifts across the Turkana depression. Tectonics 36, 1767-1786 (2017).

33. Corti, G. et al. Aborted propagation of the Ethiopian rift caused by linkage with the Kenyan rift. Nat. Commun. 10, 1309 (2019)

34. Choi, E., Lavier, L. L. \& Gurnis, M. Thermomechanics of mid-ocean ridge segmentation. Phys. Earth Planet. In. 171, 374-386 (2008).
35. Allken, V., Huismans, R. S. \& Thieulot, C. Factors controlling the mode of rift interaction in brittle-ductile coupled systems: a 3D numerical study. Geochem., Geophys., Geosyst. 13, 4077 (2012).

36. Ammann, N., Liao, J., Gerya, T. \& Ball, P. Oblique continental rifting and long transform fault formation based on $3 \mathrm{D}$ thermomechanical numerical modeling. Tectonophysics 746, 106-120 (2017).

37. Tommasi, A. \& Vauchez, A. Continental rifting parallel to ancient collisional belts: an effect of the mechanical anisotropy of the lithospheric mantle. Earth Planet. Sci. Lett. 185, 199-210 (2001).

38. van Wijk, Y. Role of weak zone orientation in continental lithosphere extension. Geophys. Res. Lett. 32, L02303 (2005).

39. Corti, G., van Wijk, Y., Cloetingh, S. \& Morley, C. K. Tectonic inheritance and continental rift architecture: numerical and analogue models of the East African Rift system. Tectonics 26, 2086 (2007).

40. Buiter, S. J. \& Torsvik, T. H. A review of Wilson Cycle plate margins: a role for mantle plumes in continental break-up along sutures? Gondwana Res. 26, 627-653 (2014)

41. Kronbichler, M., Heister, T. \& Bangerth, W. High accuracy mantle convection simulation through modern numerical methods. Geophys. J. Int. 191, 12-29 (2012).

42. Heister, T., Dannberg, J., Gassmöller, R. \& Bangerth, W. High accuracy mantle convection simulation through modern numerical methods - II: realistic models and problems. Geophys. J. Int. 210, 833-851 (2017).

43. Rose, I., Buffett, B. \& Heister, T. Stability and accuracy of free surface time integration in viscous flows. Phys. Earth Planet. In. 262, 90-100 (2017).

44. Gassmöller, R., Lokavarapu, H., Heien, E., Puckett, E. G. \& Bangerth, W. Flexible and scalable particle-in-cell methods with adaptive mesh refinement for geodynamic computations. Geochem., Geophys., Geosyst. 19, 7508 (2018).

45. Withjack, M. O. \& Jamison, W. R. Deformation produced by oblique rifting Tectonophysics 126, 99-124 (1986).

46. Autin, J. et al. Analogue models of oblique rifting in a cold lithosphere. Tectonics 29, 2671 (2010).

47. Brune, S. Evolution of stress and fault patterns in oblique rift systems: 3D numerical lithospheric-scale experiments from rift to breakup. Geochem. Geophys., Geosyst. 15, 3392-3415 (2014)

48. Acocella, V. Transform faults or overlapping spreading centers? Oceanic ridge interactions revealed by analogue models. Earth Planet. Sci. Lett. 265, 379-385 (2008).

49. Gerya, T. V. Three-dimensional thermomechanical modeling of oceanic spreading initiation and evolution. Phys. Earth Planet. In. 214, 35-52 (2013).

50. McConnell, R. B. Geological development of the rift system of Eastern Africa. GSA Bull. 83, 2549-2572 (1972).

51. LePourhiet, L., May, D. A., Huille, L., Watremez, L. \& Leroy, S. A genetic link between transform and hyper-extended margins. Earth Planet. Sci. Lett. 465, 184-192 (2017)

52. Koptev, A. et al. Plume-induced continental rifting and break-up in ultra-slow extension context: insights from 3D numerical modeling. Tectonophysics $\mathbf{7 4 6}$, 121-137 (2018b).

53. Morley, C. K. Stress re-orientation along zones of weak fabrics in rifts: an explanation for pure extension in 'oblique' rift segments? Earth Planet. Sci. Lett. 297, 667-673 (2010)

54. Delvaux, D., Kervyn, F., Macheyeki, A. \& Temu, E. Geodynamic significance of the TRM segment in the East African Rift (W-Tanzania): Active tectonics and paleostress in the Ufipa plateau and Rukwa basin. J. Struct. Geol. 37, 161-180 (2012)

55. Heidbach, O. et al. WSM world stress map database release V. 1.1. GFZ Dato Services. https://doi.org/10.5880/WSM.2016.001 (2016)

56. Neves, M. C., Searle, R. C. \& Bott, M. H. P. Easter microplate dynamics. J. Geophys. Res.: Solid Earth 108, 2213 (2003).

57. Doubrovine, P. V., Steinberger, B. \& Torsvik, T. H. Absolute plate motions in a reference frame defined by moving hot spots in the Pacific, Atlantic, and Indian oceans. J. Geophys. Res.: Solid Earth 117, 1-30 (2012).

58. Ebinger, C. J. \& Sleep, N. H. Cenozoic magmatism throughout east Africa resulting from impact of a single plume. Nature 395, pages788-791 (1998).

59. Mulibo, G. D. \& Nyblade, A. A. Mantle transition zone thinning beneath eastern Africa: Evidence for a whole-mantle superplume structure. Geophys. Res. Lett. 40, 3562-3566 (2013).

60. Pik, R., Marty, B. \& Hilton, D. R. How many mantle plumes in Africa? The geochemical point of view. Chem. Geol. 226, 100-114 (2006).

61. Halldórsson, S. A., Hilton, D. R., Scarsi, P., Abebe, T. \& Hopp, J. A common mantle plume source beneath the entire East African Rift System revealed by coupled helium-neon systematics. Geophys. Res. Lett. 41, 2304-2311 (2014)

62. Koptev, A., Cloetingh, S., Gerya, T., Calais, E. \& Leroy, S. Non-uniform splitting of a single mantle plume by double cratonic roots: Insight into the origin of the central and southern East African Rift System. Terra Nova 30, 125-134 (2017). 
63. Koptev, A., Calais, E., Burov, E., Leroy, S. \& Gerya, T. Along-axis variations of rift width in a coupled lithosphere-mantle system, application to East Africa. Geophys. Res. Lett. 45, 5362-5370 (2018).

64. Beniest, A., Koptev, A., Leroy, S., Sassi, W. \& Guichet, X. Two-branch breakup systems by a single mantle plume: insights from numerical modeling. Geophys. Res. Lett. https://doi.org/10.1002/2017GL074866 (2017).

65. Delvaux, D. \& Barth, A. African stress pattern from formal inversion of focal mechanism data. Tectonophysics 482, 105-128 (2010).

66. Corti, G., Philippon, M., Sani, F., Keir, D. \& Kidane, T. Re-orientation of the extension direction and pure extensional faulting at oblique rift margins: comparison between the Main Ethiopian Rift and laboratory experiments. Terra Nova 25, 396-404 (2013).

67. Philippon, M. et al. Slip re-orientation in oblique rifts. Geology 43, 147-150 (2015).

68. Chorowicz, J., Le Fournier, J. \& Vidal, G. A model for rift development in Eastern Africa. Geol. J. 22, 495-513 (1987).

69. Tiercelin, J. et al. East African rift system: offset, age and tectonic significance of the Tanganyika-Rukwa-Malawi intracontinental transcurrent fault zone. Tectonophysics 148, 241-252 (1988).

70. Scott, D. L., Etheridge, M. A. \& Rosendahl, B. R. Oblique-slip deformation in extensional terrains: a case study of the lakes Tanganyika and Malawi rift zones. Tectonics 11, 998-1009 (1992).

71. Wheeler, W. H. \& Karson, J. A. Extension and subsidence adjacent to a 'weak' continental transform: an example from the Rukwa Rift, East Africa. Geology 22, 625-628 (1994).

72. Shudofsky, G. N. Source mechanisms and focal depths of East African earthquakes using Rayleigh-wave inversion and bodywave modelling. Geophys. J. R. Astronom. Soc. 83, 563-614 (1985).

73. Morley, C. K. Variable extension in Lake Tanganyika. Tectonics 7, 785-801 (1988).

74. Ebinger, C. J. Tectonic development of the western branch of the East African rift system. Geol. Soc. Am. Bull. 101, 885-903 (1989)

75. Morley, C. K., Cunningham, S. M., Harper, R. M. \& Wescott, W. A. Geology and geophysics of the Rukwa rift, East Africa. Tectonics 11, 69-81 (1992).

76. Coussement, C. et al. The North Tanganyika hydrothermal fields, East African Rift system: their tectonic control and relationship to volcanism and rift segmentation. Tectonophysics 237, 155-173 (1994).

77. Lezzar, K. E. et al. Control of normal fault interaction on the distribution of major Neogene sedimentary depocenters, Lake Tanganyika, East African rift. AAPG Bull. 86, 1027-1059 (2002).

78. Strecker, M. R., Blisniuk, P. \& Eisbacher, G. H. Rotation of extension direction in the central Kenya Rift. Geology 18, 299-302 (1990).

79. Ring, U., Betzler, C. \& Delvaux, D. Normal vs. strike-slip faulting during rift development in East Africa: the Malawi rift. Geology 20, 1015-1018 (1992).

80. Mortimer, E., Paton, D. A., Scholz, C. A., Strecker, M. R. \& Blisniuk, P. Orthogonal to oblique rifting: effect of rift basin orientation in the evolution of the North basin, Malawi Rift, East Africa. Basin Res. 19, 393-407 (2007)

81. Stamps, D. S., Saria, E. \& Kreemer, C. A geodetic strain rate model for the East African Rift system. Sci. Rep. 8, 732 (2018).

82. Crameri, F. Geodynamic diagnostics, scientific visualisation and StagLab 3.0, Geosci. Model Dev., 11, 2541-2562, https://doi.org/10.5194/gmd-11-2541 2018 (2018).

83. Tugume, F., Nyblade, A., Julià, J. \& van der Meijde, M. Precambrian crustal structure in Africa and Arabia: evidence lacking for secular variation. Tectonophysics 609, 250-266 (2013).

84. Globig, J. et al. New insights into the crust and lithospheric mantle structure of Africa from elevation, geoid, and thermal analysis. J. Geophys. Res.: Solid Earth 121, 5389-5424 (2016)

85. Artemieva, I. M. Global $1^{\circ} \times 1^{\circ}$ thermal model TC1 for the continental lithosphere: Implications for lithosphere secular evolution. Tectonophysics 416, 245-277 (2006).

86. Turcotte, D. L. \& Schubert, G. Geodynamics (Cambridge University Press, 2002).

87. Lucazeau, F. Analysis and mapping of an updated terrestrial heat flow data set. Geochem., Geophys., Geosyst. 20, 4001-4024 (2019).

88. Pérez-Gussinyé, M. et al. Effective elastic thickness of Africa and its relationship to other proxies for lithospheric structure and surface tectonics. Earth Planet. Sci. Lett. 287, 152-167 (2009).

89. Audet, P. \& Bürgmann, R. Dominant role of tectonic inheritance in supercontinent cyles. Nat. Geosci. 4, 184-187 (2011).

90. Buck, W. R. 1. Consequences of Asthenospheric Variability on Continental Rifting (Columbia University Press, New York, 2004).

91. Glerum, A. C., Thieulot, C., Fraters, M., Blom, C. \& Spakman, W. Nonlinear viscoplasticity in ASPECT: benchmarking and applications to subduction. Solid Earth 9, 267-294 (2018).

92. Karato, S. \& Wu, P. Rheology of the upper mantle: a synthesis. Science $\mathbf{2 6 0}$, 771-778 (1993).
93. Rutter, E. H. \& Brodie, K. H. Experimental grain size-sensitive flow of hotpressed Brazilian quartz aggregates. J. Struct. Geol. 26, 2011-2023 (2004).

94. Rybacki, E., Gottschalk, M., Wirth, R. \& Dresen, G. Influence of water fugacity and activation volume on the flow properties of fine-grained anorthite aggregates. J. Geophys. Res.: Solid Earth 111, 3663 (2006).

95. Hirth, G. \& Kohlstedt, D. Rheology of the upper mantle and the mantle wedge: a view from the experimentalists. in Inside the Subduction Factory (ed. Eiler, J.) Vol. 183 of Geophysical Monograph (American Geophysical Union, 2003).

96. Kachanov, L. M. Fundamentals of the Theory of Plasticity (Dover Publications, Inc., 2004).

97. Huismans, R. S. \& Beaumont, C. Symmetric and asymmetric lithospheric extension: relative effects of frictional-plastic and viscous strain softening. J. Geophys. Res. 108, 2026 (2003).

98. Naliboff, J. \& Buiter, S. J. H. Rift activation and migration during multiphase extension. Earth Planet. Sci. Lett. 421, 58-67 (2015).

99. Kelly, C. T. Iterative methods for Linear and Nonlinear Equations (SIAM, 1995).

100. Roberts, E. M. et al. Initiation of the western branch of the East African Rift coeval with the eastern branch. Nat. Geosci. 5, 289-294 (2012).

101. Torres Acosta, V. et al. Cenozoic extension in the Kenya Rift from lowtemperature thermochronology: links to diachronous spatiotemporal evolution of rifting in East Africa. Tectonics 34, 2367-2386 (2015).

102. Ebinger, C. \& Scholz, C. A. Continental rift basins: the East African perspective. in Tectonics of Sedimentary Basins: Recent Avances (eds Busby, C. \& Azor, A.) Chap. 9 (Blackwell Publishin Ltd., 2012).

103. Horner-Johnson, B. C., Gordon, R. G. \& Argus, D. F. Plate kinematic evidence for the existence of a distinct plate between the Nubian and Somalian plates along the Southwest Indian Ridge. J. Geophys. Res. 112, 4519 (2007).

104. Iaffaldano, G., Hawkins, R. \& Sambridge, M. Bayesian noise-reduction in Arabia/ Somalia and Nubia/Arabia finite rotations since $\sim 20 \mathrm{Ma}$ : Implications for Nubia/Somalia relative motion. Geochem., Geophys., Geosyst. 15, 845-854 (2014).

105. DeMets, C. \& Merkouriev, S. High-resolution estimates of Nubia-Somalia plate motion since $20 \mathrm{Ma}$ from reconstructions of the Southwest Indian Ridge, Red Sea and Gulf of Aden. Geophys. J. Int. 207, 317-332 (2016).

106. Brune, S., Popov, A. A. \& Sobolev, S. V. Modeling suggests that oblique extension facilitates rifting and continental break-up. J. Geophys. Res.: Solid Earth 117, 8860 (2012)

107. Zoback, M.-L. First- and second-order patterns of stress in the lithosphere: The World Stress Map Project. J. Geophys. Res.: Solid Earth 97, 11703-11728 (1992).

\section{Acknowledgements}

This study was conducted within the Helmholtz Young Investigators Group CRYSTALS (VH-NG-1132). We thank the Computational Infrastructure for Geodynamics (geodynamics.org), which is funded by the National Science Foundation under award EAR0949446 and EAR-1550901, for supporting the development of ASPECT. Computation were performed on the German computer cluster Konrad, a HLRN facility. Figures in this paper were made with ParaView, InkScape, MATLAB, and the Generic Mapping Tools. Perceptually uniform color maps were used to prevent visual distortion of the data $^{82}$.

\section{Author contributions}

Discussions between A.G., S.B., D.S.S., and M.S. formed the basis of this paper. A.G. provided the code implementations necessary for the setup and post processing. A.G. and S.B. constructed and performed the model runs. A.G. and S.B. wrote the paper, with significant contributions from D.S.S. and M.S.

\section{Competing interests}

The authors declare no competing interests.

\section{Additional information}

Supplementary information is available for this paper at https://doi.org/10.1038/s41467 020-16176-x.

Correspondence and requests for materials should be addressed to A.G.

Peer review information Nature Communications thanks Ritske Huismans, Laetitia Le Pourhiet and the other, anonymous, reviewer(s) for their contribution to the peer review of this work.

Reprints and permission information is available at http://www.nature.com/reprints

Publisher's note Springer Nature remains neutral with regard to jurisdictional claims in published maps and institutional affiliations. 
(c) (i) Open Access This article is licensed under a Creative Commons Attribution 4.0 International License, which permits use, sharing, adaptation, distribution and reproduction in any medium or format, as long as you give appropriate credit to the original author(s) and the source, provide a link to the Creative Commons license, and indicate if changes were made. The images or other third party material in this article are included in the article's Creative Commons license, unless indicated otherwise in a credit line to the material. If material is not included in the article's Creative Commons license and your intended use is not permitted by statutory regulation or exceeds the permitted use, you will need to obtain permission directly from the copyright holder. To view a copy of this license, visit http://creativecommons.org/ licenses/by/4.0/.

(C) The Author(s) 2020 